Original Research Article

\title{
Amelioration of Tau pathology and memory deficits by targeting 5-HT7 receptor
}

\author{
Josephine Labus $^{\text {a,1 }}{ }^{\text {, Kian-Fritz Röhrs }}{ }^{\text {a,b,1, Jana Ackmann }}{ }^{\text {a }}$, Hristo Varbanov ${ }^{\text {c,d }}$, \\ Franziska E. Müller ${ }^{a}$, Shaobo Jia ${ }^{\mathrm{d}}$, Kathrin Jahreis ${ }^{\mathrm{a}}$, Anna-Lena Vollbrecht ${ }^{\mathrm{a}}$, Malte Butzlaff ${ }^{\mathrm{a}}$, \\ Yvonne Schill $^{\text {a }}$, Daria Guseva ${ }^{a}$, Katrin Böhm ${ }^{\mathrm{d}}$, Rahul Kaushik ${ }^{\mathrm{d}, \mathrm{e}}$, Monika Bijata ${ }^{\mathrm{a}, \mathrm{f}}$, \\ Philippe Marin ${ }^{g}$, Séverine Chaumont-Dubel ${ }^{g}$, Andre Zeug ${ }^{a}$, Alexander Dityatev ${ }^{\mathrm{d}, \mathrm{e}, \mathrm{h}, * *}$, \\ Evgeni Ponimaskin ${ }^{a, i, *}$
}

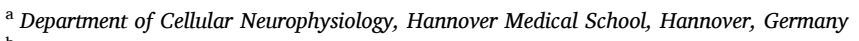

${ }^{\mathrm{b}}$ Department of Neurology, Charité - Universitätsmedizin Berlin, Berlin, Germany

${ }^{\mathrm{c}}$ Instituite of Neurophysiology, Hannover Medical School, Hannover, Germany

${ }^{\mathrm{d}}$ German Center for Neurodegenerative Diseases (DZNE), Magdeburg, Germany

${ }^{\mathrm{e}}$ Center for Behavioral Brain Sciences (CBBS), Magdeburg, Germany

${ }^{\mathrm{f}}$ Department of Molecular and Cellular Neurobiology, Nencki Institute of Experimental Biology of the Polish Academy of Science, Warsaw, Poland

${ }^{\mathrm{g}}$ IGF, Université de Montpellier, CNRS, INSERM, Montpellier, France

${ }^{\text {h }}$ Medical Faculty, Otto-von-Guericke University, Magdeburg, Germany

${ }^{\mathrm{i}}$ Institute of Neuroscience, Lobachevsky State University of Nizhni Novgorod, Russia

\section{A R T I C L E I N F O}

\section{Keywords:}

5-HT7 receptor

CDK5

Dementia

Serotonin

Tauopathies

\begin{abstract}
A B S T R A $\mathrm{T}$
Tauopathies comprise a heterogeneous family of neurodegenerative diseases characterized by pathological accumulation of hyperphosphorylated Tau protein. Pathological changes in serotonergic signaling have been associated with tauopathy etiology, but the underlying mechanisms remain poorly understood. Here, we studied the role of the serotonin receptor 7 (5-HT7R), in a mouse model of tauopathy induced by overexpressing the human Tau[R406W] mutant associated with inherited forms of frontotemporal dementia. We showed that the constitutive 5-HT7R activity is required for Tau hyperphosphorylation and formation of highly bundled Tau structures (HBTS) through G-protein-independent, CDK5-dependent mechanism. We also showed that 5-HT7R physically interacts with CDK5. At the systemic level, 5-HT7R-mediated CDK5 activation induces HBTS leading to neuronal death, reduced long-term potentiation (LTP), and impaired memory in mice. Specific blockade of constitutive 5-HT7R activity in neurons that overexpressed Tau[R406W] prevents Tau hyperphosphorylation, aggregation, and neurotoxicity. Moreover, 5-HT7R knockdown in the prefrontal cortex fully abrogates Tau [R406W]-induced LTP deficits and memory impairments. Thus, 5-HT7R/CDK5 signaling emerged as a new, promising target for tauopathy treatments.
\end{abstract}

\section{Introduction}

Multiple neurodegenerative diseases, such as Alzheimer's, Parkinson's, and Huntington's disease, as well as amyotrophic lateral sclerosis are characterized by the formation and deposition of protein aggregates, either inside or outside of neurons, within certain brain areas. In particular, aggregation of the microtubule-associated protein, Tau, leads to the development of so-called tauopathies. Tauopathies are generally

\footnotetext{
Abbreviations: AAV, adeno-associated virus; AD, Alzheimer's disease; CDK5, cyclin-dependent kinase 5; FTDP-17, frontotemporal dementia with parkinsonism

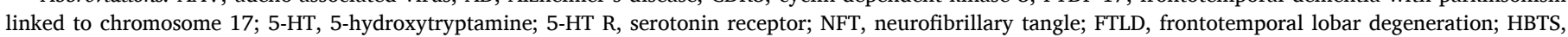

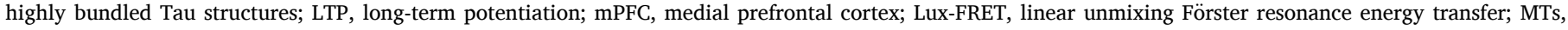
microtubules; PHFs, paired helical filaments; WT, wild type; KO, knockout; GSK3 $\beta$, glycogen synthase kinase 3 beta.

* Corresponding author at: Hannover Medical School, Carl-Neuberg-Str. 1, 30625 Hannover, Germany.

** Corresponding author at: Deutsches Zentrum für Neurodegenerative Erkrankungen (DZNE), Leipziger Str. 44, 39120 Magdeburg, Germany.

E-mail addresses: alexander.dityatev@dzne.de (A. Dityatev), Ponimaskin.Evgeni@mh-hannover.de (E. Ponimaskin).

1 These authors contributed equally.
} 
characterized by the deposition of hyperphosphorylated, aggregated Tau protein within neurons (Arendt et al., 2016). The most prominent members in this class of diseases are Alzheimer's disease (AD) and frontotemporal lobar degeneration (FTLD), which cause the majority of dementia cases worldwide (Duthey, 2013). Intracellular inclusions that include Tau are also found in several other neurodegenerative diseases, including Pick disease, progressive supranuclear palsy, corticobasal degeneration, and frontotemporal dementia with parkinsonism linked to chromosome 17 (FTDP-17) (Josephs, 2017).

Under physiological conditions, Tau participates in regulating microtubule network dynamics by binding to and stabilizing microtubules (MTs). Tau also promotes tubulin polymerization, and it is known to influence cell morphology, axonal outgrowth, and axonal cargo transport (Wang and Mandelkow, 2015). Tau's functions are mainly regulated by phosphorylation at multiple sites, which are mediated by a variety of defined kinases (Buee et al., 2000). Under pathological conditions, Tau phosphorylation is drastically increased, which results in reduced microtubule binding affinity and the aggregation of Tau protein. In turn, this leads to a destabilized microtubule network, impaired axonal transport, inhibited proteasomal degradation pathways, and dysfunctional mitochondria (Arendt et al., 2016). Several point mutations within the Tau gene, located on chromosome 17, have been shown to boost Tau aggregation (Goedert and Jakes, 2005). One of these mutations, Tau[R406W], which causes FTDP-17, remained prone to aggregation, due to its reduced capacity to bind to and nucleate MTs (Hong et al., 1998; Perez et al., 2000, p. 17; Sakaue et al., 2005). In many cases, Tau aggregates become neurofibrillary tangles (NFTs), which are composed of paired helical filaments (PHF) (Grundke-Iqbal et al., 1986; KIDD, 1963). It has been shown that NFTs can spread throughout the brain via prion-like mechanisms (Clavaguera et al., 2009; Lee et al., 2011). Post-mortem brain studies revealed that NFTs were often present in brain regions that exhibited massive neuronal death and severe cytological abnormalities; those findings led to the notion that aggregated Tau and NFTs might be responsible for the progression of AD and other Tau-related frontotemporal dementias (Gomez-Isla et al., 1997).

During the last decade, the serotonergic system regained attention as a potential target for the treatment of neurodegenerative diseases, in particular AD (Butzlaff and Ponimaskin, 2016; Rodríguez et al., 2012). The number of serotonergic neurons is decreased in the raphe nuclei of patients with AD (Chen et al., 2000; Kovacs et al., 2003; Zweig et al., 1988). Moreover, administration of selective serotonin reuptake inhibitors reduced the production of toxic amyloid proteins and amyloid plaques in mouse models of AD (Cirrito et al., 2011; Sheline et al., 2014). Several serotonin receptors, including 5-HT4R, are known to modulate the processing of the amyloid beta protein precursor (Cochet et al., 2013; Thathiah and De Strooper, 2011). Furthermore, administration of 5-HT6R antagonists improved cognitive performance in rodent models of $\mathrm{AD}$ (Upton etal., 2008). On the other hand, a recent clinical study in patients with mild to moderate $\mathrm{AD}$ demonstrated that the use of the 5-HT6R antagonist, idalopirdine, did not improve cognition (Atri et al., 2018). While the effects of the 5-HT4R in AD treatments might result from its influence on amyloid $\beta$ protein processing via modulation of corresponding secretase activities $(e$. g., ADAM10 or BACE1), the role of serotonin receptors in Tau hyperphosphorylation and NFT formation remains to be elucidated.

Here, we investigated a potential role of the 5-HT7R in Tau-related pathology. In the human brain, the 5-HT7R is highly expressed in the hippocampus and cerebral cortex, areas that are primarily affected by AD and FTLD (Hedlund and Sutcliffe, 2004). Moreover, genome-wide screens have revealed single-nucleotide polymorphisms located in close proximity to the 5-HT7R gene in patients with AD (Liu et al., 2007). The 5-HT7R is coupled to two heterotrimeric G-proteins, Gs and G12. Receptor-mediated Gs activation leads to stimulation of adenylate cyclase, which in turn, results in increasing cAMP levels. Receptor coupling to the G12 protein leads to the activation of two small GTPases of the Rho family, Cdc42 and RhoA (Kobe et al., 2012; Kvachnina, 2005a; Wirth et al., 2016). In the present study, we highlighted that the constitutive activity of 5-HT7R induced Tau hyperphosphorylation, Tau aggregation, and the formation of highly bundled Tau structures (HBTS) in neuroblastoma cells, in primary neuronal cultures, and in cortical neurons in vivo. We also elucidated the underlying molecular machinery by demonstrating a physical interaction between 5-HT7R and the Tau kinase, CDK5 leading to a G-protein-independent activation of CDK5. Finally, we demonstrated the therapeutic potential of the 5-HT7R by showing that selective knockdown of the 5-HT7R in the prefrontal cortex (PFC) of mice abrogated the deleterious effects of Tau[R406W] overexpression in this region on synaptic plasticity and cognition.

\section{Material and methods}

\subsection{Cell culture and transfection}

The neuroblastoma cell line N1E-115 (American Type Culture Collection) was cultured and maintained in Dulbecco's modified Eagle's medium with $10 \% \mathrm{FBS}$ and $1 \%$ of penicillin/streptomycin at $37^{\circ} \mathrm{C}$ and 5 $\%$ CO2. For transient transfection, we applied Lipofectamine 2000 reagent (Life technologies) according to the manufacturer's instructions. For transfection, we used plasmids encoding: eGFP-tagged Tau[R406W] mutant, eGFP-tagged Tau WT, Tau[P301L]-TurboGFP (a gift of Yun Kyung Kim, KIST, South Korea), HA-tagged 5-HT7R, HA-tagged 5HT1AR, HA-tagged 5-HT2R, HA-tagged 5-HT6R, CDK5-mCherry, CDK5-K33T-mCherry (CDK5-DN) under the control of a CMV promotor, shRNA directed against the $\alpha$-subunit of the G12 protein (Oligoengine), shRNA directed against CDK5 (5'-TGACCAAGCTGCCAGACTATA- $\left.3^{\prime}\right)$ and scrambled shRNA ( $5^{\prime}$-ACTACCGTTGTTATAGGTG-3') under the control of a $\mathrm{H} 1$ promotor. For treatments, we applied $100 \mathrm{nM}$ of the selective 5HT7R inverse agonist SB-269970 (Tocris), $20 \mu \mathrm{M}$ of the CDK5 inhibitor roscovitine, $10 \mu \mathrm{M}$ of the GSK3 inhibitor SB-216763 or $20 \mu \mathrm{M}$ 5-hydroxytryptamine (5-HT).

\subsection{Primary cortical neurons and viral infection}

Mice were bred at the central animal facility of Hannover Medical School. Following mice strains of either sex were used: C57BL/6 JHanZtm (wild type, WT), C57BL/6 J-Htr7tm1Sut (5-HT7R knockout, 5HT7R KO) (Hedlund et al., 2003). Cultures of primary cortical neurons were prepared according to a previously published method (Speranza et al., 2013). At DIV 10, cultured cortical neurons were infected with $10^{7}$ virus copies of indicated AAVs per each well in 12-well-plate, and analyzed three days post-infection.

\subsection{Preparation of adeno-associated viruses}

The following mono-cistronic viral vectors with a synapsin promotor as well as bi-cistronic viral vectors with a $\mathrm{H} 1$ and a synapsin promotor were constructed: pAAV_Syn-eGFP, pAAV_Syn-eGFP-Tau[R406W], pAAV_H1-scramble-shRNA_Syn-eGFP, pAAV_H1-5-HT7R-shRNA_SyneGFP (Supplementary Fig. 8A, B, D). Following target sequences for the shRNA were used: scramble (scr) 5'-ACTACCGTTGTTATAGGTG-3'; anti5-HT7R 5'-TCCTTTATCATTATGGTGT-3'. Adeno-associated viruses (AAV) were produced using the AAV-DJ Packaging System from CELL BIOLABS in HEK293 cells. Briefly, HEK 293 cell were transfected with a pAAV plasmid encoding the gene of interest along with a pHelper plasmid as well as a pAAV-DJ plasmid. After three days, AAVs were harvested by three freezing and thawing cycles followed by benzonase digest. AAVs were concentrated using Amicon centrifugation tubes with a cut off of $10 \mathrm{kDa}$. For titer determination virus capsid was digested using protein $\mathrm{K}$, and virus DNA was analyzed using quantitative realtime polymerase chain reaction (qRT-PCR) with primers against the viral WPRE element (fw $5^{\prime}$ - CCTGGTTGCTGTCTCTTTATGAGG-3'; rev 5'- TGACAGGTGGTGGCAATGC-3'; probe 5'-/6-FAM/ CGTTGTCAGGCAACGTGG CGTGGTG/TAMRA/-3' (Sigma). For calculation of the viral gene copy number per $\mu$ l the relative standard curve method was used. 


\subsection{Quantitative real-time polymerase chain reaction}

The total RNA from N1E-115 cells, neurons or brain tissue was isolated using RNeasy Mini Kit (Qiagen) and transcribed using SuperScript ${ }^{\circledR}$ III First-Strand Synthesis System (Invitrogen). The expression analysis was performed on a StepOne System (Applied Biosystems) using TaqMan Universal PCR Master Mix (Applied Biosystems). Gene Expression Assays (ThermoFisher) were used for the detection of 5HT7R (Mm00434133_m1) and Go12 mRNA (Mm00494667_m1), CDK5 (Mm00432447_g1), human Tau (Hs00902194_m1) and mouse Tau (Mm005211988m1). Calculation of relative mRNA levels was performed by using the $\Delta \Delta \mathrm{Ct}$ method.

\subsection{Western blot}

For the Western blot analysis, equal amounts of protein were separated on SDS-polyacrylamide gels. Proteins were then transferred onto nitrocellulose membranes and probed with the following antibodies: pT181-Tau AT270 (1:2,000, Thermofisher), pSer199-Tau (1:1,1000, Abcam), pSer202-Tau (1:1,1000, Abcam), pThr205-Tau (1:1,1000, Abcam), pSer396-Tau (1:1,1000, Abcam), Tau 5A6 (1:500, The Developmental Studies Hybridoma Bank DSHB), Tau-5 (1:2,000, Cell signaling), anti-GAPDH (1:10,000, Millipore), anti-CDK5 (1:1,000, Cell Signaling), anti-GSK3 (1:2,000), anti-G $\alpha 12$ (1:500, Santa Cruz Biotechnology SCBT), anti-mCherry (1:1,000, SICGEN), anti-HA (1:500, Carl Roth), HRP-conjugated anti-eGFP (1:500, Biozol).

\subsection{Sarkosyl fractionation}

Sarkosyl fractionation was performed according to the protocol described earlier (Jo et al., 2014). Briefly, N1E-115 cells were scraped of in $100 \mu$ lice-cold MES-buffer (0.1 M MES (pH 7.0), 1 mM EDTA, 0.5 mM $\mathrm{MgSO}_{4}, 1 \mathrm{M}$ sucrose, $1 \mathrm{mM} \mathrm{NaF}, 1 \mathrm{mM} \mathrm{Na} \mathrm{VO}_{4}$, PMSF, CLAP) and homogenized using a tissue grinder. Homogenates were centrifuged for 5 min at $500 \mathrm{~g}$ at $4{ }^{\circ} \mathrm{C}$ to remove nuclei and cellular debris. The supernatant was centrifuged at $50,000 \mathrm{~g}$ for $20 \mathrm{~min}$ at $4{ }^{\circ} \mathrm{C}$ and the resulting supernatant was collected as "soluble fraction" and incubated at $95{ }^{\circ} \mathrm{C}$ with $20 \mu \mathrm{l} 6 \mathrm{x}$ SDS for $5 \mathrm{~min}$. The pellet was resuspended in $50 \mu \mathrm{l}$ RAB-Buffer (100 mM MES (pH 6.8), $10 \%$ sucrose, 2 mM EGTA, 0.5 mM $\mathrm{MgSO}_{4}, 500 \mathrm{mM} \mathrm{NaCl}, 1 \mathrm{mM} \mathrm{MgCl} 2,10 \mathrm{mM} \mathrm{NaH}_{2} \mathrm{PO}_{4}, 20 \mathrm{mM} \mathrm{NaF}, 1 \%$ $N$-lauroylsarcosine (Sarkosyl), CLAP, PMSF), vortexed for $1 \mathrm{~min}$ at room temperature, incubated overnight at $4{ }^{\circ} \mathrm{C}$ and then centrifuged at 200, $000 \mathrm{~g}$ for $30 \mathrm{~min}$ at room temperature. The supernatant was collected as "sarkosyl-soluble fraction", the pellet was collected as "insoluble fraction" and incubated in $60 \mu \mathrm{l} 1 \mathrm{x}$ SDS at $95{ }^{\circ} \mathrm{C}$ for $5 \mathrm{~min}$.

\subsection{Analysis of Tau distribution in N1E-115 cells and primary cortical neurons}

N1E-115 cells were transfected either with eGFP-Tau[R406W], eGFP or eGFP-Tau [R406W] in combination with CDK5-WT-mCherry or CDK5DN-mCherry and fixed using ice-cold methanol. In primary cortical neurons, cells isolated from WT or 5-HT7R KO mice were infected with AAVeGFP-Tau[R406W] or AAV-eGFP at DIV10 and fixed at DIV13. Cells were covered with Fluomount-G and analyzed in a blinded fashion using a Till ID IMIC wide-field microscope. Cells containing broad bands enriched in eGFP-Tau[R406W] mutant were referred to as cells with highly bundled Tau structures (Supplementary Fig. 6B). For quantitative analysis, cells with HBTS as well as the total number of eGFP-positive cells were counted, and the fraction of cells containing HBTS structures was calculated.

\subsection{Co-immunoprecipitation}

Co-immunoprecipitation from cortex homogenates was performed according to (Renner et al., 2012). Briefly, cortices isolated from P6 C57BL/6 J mice were homogenized, and membrane fractions were prepared by differential centrifugation. Lysates were incubated with a rabbit polyclonal antibody directed against the murine 5-HT7R $(10 \mu \mathrm{g}$; Santa Cruz) followed by incubation with Protein-A sepharose, SDS-PAGE and Western blot with mouse-anti-CDK5 (1:1,000; Cell Signaling) or rabbit-anti-5-HT7R (1:1,000; Abcam).

\subsection{Lux-FRET analysis}

Linear unmixing Förster resonance energy transfer (Lux-FRET) measurements were conducted as described previously (Wlodarczyk et al., 2008). For image acquisition we used a total internal reflection (TIRF) microscope setup (FEI/Till ID IMIC). For image analysis and evaluation, custom-written MATLAB scripts were used. The eCFP-tagged 5-HT7R and eYFP-tagged CDK5 were used as a donor and acceptor, respectively. Cells were imaged with the TIRF-iMIC setup with two excitation wavelengths: $440 \mathrm{~nm}$ and $514 \mathrm{~nm}$. We calculated the predicted apparent FRET efficiency $E f_{D A}=\frac{1}{2} E f_{D} /\left(1-x_{D}\right)=\frac{1}{2} E f_{A} / x_{D}$ assuming a standard dimerization model.

\subsection{Immunocytochemistry}

For the analysis of 5-HT7R, CDK5 and VGLUT-1 distribution in dissociated neurons derived from prefrontal cortex, cultured cells were fixed at DIV14. 5-HT7R was detected using primary antibody rabbit polyclonal anti-5-HT7R (1:100; Acris) and donkey anti-rabbit DyLight 649 conjugated (1:400, Jackson ImmunoResearch Laboratories). For CDK5 and VGLUT1 detection, we used primary mouse monoclonal antiCDK5 antibody (1:100, Cell Signaling) and guinea pig polyclonal antiVGLUT-1 antibody (1:1,000, Synaptic Systems), respectively. As secondary antibodies we applied donkey anti-mouse DyLight 549 conjugated and donkey anti-guinea pig DyLight 488 conjugated antibodies (Jackson ImmunoResearch Laboratories, all diluted 1:400 in PBS containing $3 \%$ BSA). To visualize hyperphosphorylation of Tau, fixed cells were incubated overnight with phospho-Tau antibody AT8 (1:100, Thermofisher) as well as the corresponding Dylight649 conjugated secondary antibody (1:400, Jackson ImmunoResearch Laboratories). To analyze Tau and MT co-localization, cells were fixed in methanol and incubated overnight with mouse-anti- $\alpha$ tubulin antibody (1:500, GeneTex) or rabbit-anti- $\beta$ III tubulin antibody (1:1000, Biolegend) followed by incubation with the corresponding AlexaFluor594 conjugated secondary antibodies (1:400, Jackson ImmunoResearch Laboratories). The coverslips were mounted in anti-quenching medium (Fluoromount G, Southern Biotechnology Associates, Biozol, Germany) and subjected for imaging analysis with a confocal microscope Zeiss LSM780 equipped with a $40 \mathrm{x}$ water-immersion objective.

\subsection{Quantitative image analysis}

To calculate to which extend Tau binds MT in N1E-115 cells, colocalization was calculated according to Manders (Manders et al., 1993) as $M_{1}=\frac{\sum_{i} T^{i} u_{c o l o c, i}}{\sum_{i} \operatorname{Tau}_{i}}$, where $T a u_{\text {coloc }, i}$ and $M T_{\text {coloc }, i}$ are intensities of the Tau and MT pixels where the corresponding microtubule and Tau pixel is above a certain threshold, respectively. As the threshold, we used the triangle method (Zack et al., 1977). Since $M_{1}$ is sensitive to the threshold method used we provide both information.

To calculate normalized fluorescence intensities for Tau and MT in cortical neurons, the mean fluorescence intensities were quantified pixel-based in a defined region of interest. Absolute intensities for each channel were normalized to the median of cells without HBTS.

\subsection{Apoptosis assay}

To investigate neuronal cell death, we applied the CellEvent ${ }^{\mathrm{TM}}$ Caspase-3/7 Green Detection Reagent (Thermo Fisher). At DIV13 
fluorogenic substrate of caspase 3 and 7 was added to the culturing medium to a final concentration of $2 \mu \mathrm{M}$. After incubation for $30 \mathrm{~min}$, cells were fixed and covered with Fluomount-G. Apoptotic neurons were identified by leading to visible fluorescence emission of cleaved substrate at $530 \mathrm{~nm}$. Quantification was performed by the experimenter blinded to the experimental conditions.

\subsection{Stereotaxic injections}

For stereotaxic delivery of AAVs, 2- to 5-month-old C57BL6/J mice, bred at the German Center of Neurodegenerative Diseases, were anesthetized using isoflurane as previously described (Minge et al., 2017). After checking the absence of withdrawal reflex to foot pinch, a longitudinal cut (5-7 mm long) was made through the shaved skin, the periosteum was removed, and two holes $(0.5 \mu \mathrm{m})$ were drilled through the skull bone using a dental micromotor (Eickemeyer, Germany) at coordinates: $+1.7 \mathrm{~mm}$ anterior-posterior (relative to bregma) and $\pm 0.3 \mathrm{~mm}$ medial-lateral (relative to midline), according to the mouse brain atlas (Franklin and Paxinos, 2008). Appropriate volumes of AAVs (500 nl per site for AAV-eGFP and AAV-eGFP-Tau[R406W] and $750 \mathrm{nl}$ per site for 1:1 mixtures of AAV- eGFP-Tau[R406W] plus AAV-5HT7R-shRNA-eGFP and AAV-Tau[R406W] plus AAV-scr-shRNA-eGFP) were bilaterally injected in the prefrontal cortex at an injection rate of $2 \mathrm{nl} / \mathrm{s}$. For injections, we used an infusion system (UltraMicroPump, UMP3, and Micro4 Controller, WPI, Germany) equipped with a $10 \mu \mathrm{l}$ Hamilton syringe and a beveled needle (NanoFil, $135 \mu \mathrm{m}, 35 \mathrm{GA}$ ).

\subsection{Electrophysiological recordings in prefrontal brain slices}

Cortical brain slices were prepared from 3- to 5-month-old C57BL6/J mice 4-6 weeks after AAV injection. After quick cervical dislocation and decapitation, the brain was isolated and transferred into ice-cold artificial cerebrospinal fluid (aCSF) continuously supplied with $95 \%$ $\mathrm{O}_{2} / 5 \% \mathrm{CO}_{2}$. The aCSF for slicing contained (in $\mathrm{mM}$ ): 250 sucrose, 24 $\mathrm{NaHCO}_{3}, 25$ glucose, $2.5 \mathrm{KCl}, 1.25 \mathrm{NaH}_{2} \mathrm{PO}_{4}, 2 \mathrm{CaCl}_{2}$, and $1.5 \mathrm{MgCl}_{2}$ (osmolarity 345-350 mOsm $/ \mathrm{kg}, \mathrm{pH} 7.4$ ). Depending on the spread of eGFP expression, coronal mPFC slices $(400 \mu \mathrm{m}$ thick), which contained the prelimbic, infralimbic, and cingulate cortices $(+1.9-1.1 \mathrm{~mm}$ relative to bregma), were cut using a VT1200S vibratome (Leica, Germany). After cutting, the slices were placed in a custom-built slice holding chamber filled with $95 \% \mathrm{O}_{2} / 5 \% \mathrm{CO}_{2}$-bubbled recording aCSF (osmolarity 300-305 mOsm $/ \mathrm{kg}, \mathrm{pH} 7.4$ ), in which the sucrose content was completely substituted by $120 \mathrm{mM} \mathrm{NaCl}$.

Field excitatory postsynaptic potentials (fEPSPs) were evoked in layer II-III and recorded in layer V of the mPFC using thin-walled glass electrodes (borosilicate glass, $0.188 \times 100 \times 1.5 \mathrm{~mm}$, Hilgenberg, Germany). When filled with recording aCSF, the tip resistance for the stimulation and recording glass electrodes was $0.3-0.5 \mathrm{M} \Omega$ and 2-2.5 $\mathrm{M} \Omega$, respectively. All recordings were performed at room temperature $\left(22-25{ }^{\circ} \mathrm{C}\right)$. Only slices expressing eGFP in the mPFC were taken for recordings.

For each slice, stimulus-response curves were computed by plotting the relationship between mean fEPSP slope and stimulus intensity. For baseline recording before LTP induction, we recorded 30 fEPSPs evoked at $0.05 \mathrm{~Hz}(10 \mathrm{~min})$. In each slice, baseline fEPSP recording and the following long-term potentiation (LTP) were recorded at $\sim 50 \%$ of the supramaximal stimulation intensity as previously described (Brennaman et al., 2011). For induction of LTP, five trains of theta-burst stimulation (TBS) with an inter-theta-train interval of $20 \mathrm{~s}$ were applied ( 8 bursts per train at $5 \mathrm{~Hz} ; 4$ pulses per burst at $100 \mathrm{~Hz} ; 0.2 \mathrm{~ms}$ pulse duration).

Signals were acquired at a sampling rate of $10 \mathrm{kHz}$ and low-pass filtered at $500 \mathrm{~Hz}$ using an EPC10 amplifier and the PatchMaster software. All electrophysiological data were analyzed and presented using PatchMaster and Adobe Illustrator CS5 (Adobe Systems Inc., San Jose, CA, USA). For clarity, the stimulus artefacts in all examples for mPFC fEPSPs were blanked. Recordings were not included in data analysis, if they showed changes $(>20 \%)$ in the amplitude of presynaptic fiber volley (before and after TBS) or if the level short-term potentiation (first 1 min after TBS) was $<150 \%$. For statistical analysis, SigmaPlot 12 software was used to perform statistical comparisons of LTP levels between independent groups using unpaired Student's t tests (significance level of 0.05).

\subsection{Immunohistochemistry}

To analyze 5-HT7R and CDK5 localization, brains were isolated from wild-type P6 mice and fixed with $4 \%$ formaldehyde in PBS, pH 7.3, for 3 days at $4{ }^{\circ} \mathrm{C}$ and then immersed in $15 \%$ sucrose solution in $0.1 \mathrm{M}$ cacodylate buffer, $\mathrm{pH} 7.3$, for 1 day at $4{ }^{\circ} \mathrm{C}$, followed by $30 \%$ sucrose solution for 1 day at $4{ }^{\circ} \mathrm{C}$. Afterwards the tissue was frozen for $2 \mathrm{~min}$ in 2-methylbutane (isopentane, Carl Roth, Germany) precooled to $-30{ }^{\circ} \mathrm{C}$. For sectioning, the brain was attached to a cryostat specimen holder using TissueTek ${ }^{\circledR}$ (Sakura Finetek Europe, Zoeterwoude, Netherlands). Serial frontal brain sections of $20 \mu \mathrm{m}$ thickness were cut on a cryostat (Microm HM560 M, Microm GmbH, Germany) and picked up on SuperFrost ${ }^{\circledR} P l u s$ glass slides (Roth, Germany). The sections were air-dried for at least $1 \mathrm{~h}$ at room temperature (RT) and used for immunofluorescence analysis. Immunofluorescence analysis was performed using commercial antibodies at optimal dilutions as described before (Guseva et al., 2009). The sections were subjected to antigen retrieval by immersion into $0.01 \mathrm{M}$ citric acid (pH 6.0), heated to $95^{\circ} \mathrm{C}$ in a water bath for $30 \mathrm{~min}$. Blocking of non-specific binding sites was then performed using PBS containing $0.2 \%$ Triton X-100 (Sigma), $0.02 \%$ sodium azide (Merck, Germany) and $5 \%$ normal donkey serum for $1 \mathrm{~h}$ at RT. Incubation with primary antibodies against CDK5 (1:100, SCBT) and 5-HT7R (1:100, Acris), diluted in PBS containing $0.5 \%$ lambda-carrageenan (Sigma) and $0.02 \%$ sodium azide, was carried out at $4{ }^{\circ} \mathrm{C}$ for 3 days. After washing in PBS, appropriate Alexa594- and Alexa488-conjugated secondary antibodies (Jackson ImmunoResearch Europe, UK) diluted 1:200 in PBS-carrageenan solution were applied for $2 \mathrm{~h}$ at RT. After a subsequent washing in PBS, cell nuclei were stained for $10 \mathrm{~min}$ at RT with bis-benzimide solution (Hoechst 33258 dye, $5 \mu \mathrm{g} / \mathrm{mL}$ in PBS, Sigma) and the sections were mounted in anti-quenching medium. Specificity of staining was controlled by omitting the primary antibody or replacing it by an equivalent amount of non-immune IgG or serum derived from the same species as the specific antibody.

To investigate the expression of Tau in the MPFC of AAV-injected mice after electrophysiological recordings, coronal 400- $\mu \mathrm{m}$-thick mPFC slices (two slices per mouse) were fixed in $4 \%$ paraformaldehyde in phosphate buffer ( $\mathrm{PB}, 0.24 \mathrm{M}, \mathrm{pH}=7.2$ ) for $1-2 \mathrm{~h}$ at room temperature (RT) and cryoprotected using $30 \%$ sucrose in $\mathrm{PB}$ at $4{ }^{\circ} \mathrm{C}$ overnight. The sections were then mounted on a CM1950 cryostat (Leica Biosystems) using a tissue freezing medium (Jung, Leica Microsystems), and $35 \mu \mathrm{m}$-thick subsections were prepared. After cryo-sectioning, slices were stored in cryo-protective solution (25\% glycerin (Carl Roth, Karlsruhe, Germany), 25 \% ethylene glycol (Carl Roth) in 0.24 M PB) and stained "free-floating" using immunohistochemistry, as described below.

To investigate the effect of knockdown of 5HT7R on the levels of pTau in the mPFC of AAV-eGFP-Tau[R406W]-injected mice, we performed immunohistochemistry with two different pTau antibodies, rabbit anti-pTau (pT205, ab4841, Abcam, UK) and mouse anti-pTau (AT8, MN 1020, Life Technologies). Briefly, 35-40 $\mu \mathrm{m}$ cryosections from PFA fixed and $30 \%$ sucrose cryoprotected acute PFC slices or brain sections were used. After washing in PBS $(3 \times 10 \mathrm{~min}$ at RT), slices were permeabilized in $0.5 \%$ Triton X-100 (T9284, Sigma Aldrich) in PB for 10 min followed by incubation in blocking solution 1 [10\% normal goat serum (NGS, 16210-064, Life Technologies), $0.4 \%$ Triton X-100 and 0.1 $\%$ glycine (50046, Sigma Aldrich) in PB] at RT for 60 min before the immunostaining with rabbit anti-pTau. The blocking solution $2[10 \%$ NGS, $0.4 \%$ Triton X-100, $0.1 \%$ glycine and $1: 300$ goat $F(a b)$ anti-mouse IgG (ab6668, Abcam) in PB] was applied at RT for 60 min before the staining with the mouse AT8 antibody. Sections were incubated with a 
rabbit anti-pTau (1:500 in PB containing $5 \%$ NGS and $0.2 \%$ Triton X100 , at $4{ }^{\circ} \mathrm{C}$ for $48 \mathrm{~h}$ ) or mouse anti-pTau (1:100 in PB containing $5 \%$ NGS and $0.2 \%$ Triton X-100, at $4{ }^{\circ} \mathrm{C}$ for $48 \mathrm{~h}$ ). Sections were washed in PBS $(3 \times 10 \mathrm{~min}$ at RT) and incubated with secondary antibody (1:1000, goat anti-rabbit Alexa 546, 11030, Life Technologies) in their respective blocking buffers for $3 \mathrm{~h}$ at RT. then, sections were washed three times in PB for 10 min each, incubated with 4',6'-diamidino-2-phenylindole, dihydrochloride (DAPI, D1306, Life Technologies, 1:500 in PB) for 10 min, washed again twice in PB for 10 min and mounted on glass slides using Fluoromount (Cat-No: F4680, Sigma Aldrich). Imaging of pTau staining was performed on a confocal laser-scanning microscope (LSM 700, Carl Zeiss, Germany) using $10 \mathrm{x}$ and $63 \mathrm{x}$ objectives, and the confocal images were analyzed using Zen software (Carl Zeiss, Germany) and ImageJ 1.46 software (NIH, USA). To take into account individual variability in infection levels, mean pTau immunofluorescence intensity per section was normalized using the corresponding eGFP signal, which is proportional to eGFP-Tau expression level in AAV-eGFPTau[R406W] treated groups. Because the eGFP-Tau signal is lower than eGFP signal, additional normalization by mean Tau-eFGP and eGFP values (averaged per all animals) was done to compare AAV-eGFP- and AAV-eGFP-Tau[R406W]-treated groups. Mostly, two sections were stained per animal and the mean pTau/eGFP value per animal was used for statistical analysis. One slice per animal was stained omitting the AT8 primary antibody and the individual AT8 background levels were estimated and subtracted.

\subsection{Behavioral experiments}

One month after AAV injection, mice were subjected to open field test and then recent object recognition test (hereafter mentioned as the "recency test"). During the open field test, animals were exposed to an open field arena $(50 \times 50 \times 30 \mathrm{~cm})$ for $10 \mathrm{~min}$ (Prut and Belzung, 2003). The "recency" test comprised of two encoding phases followed by a retrieval phase (modified from (Nelson et al., 2011)). The interval between the encoding phases was $90 \mathrm{~min}$, and the interval between the second encoding phase and the retrieval phase was also $90 \mathrm{~min}$. In the first encoding phase, animals were placed into the open field arena and allowed to explore a pair of identical objects for $10 \mathrm{~min}$. Then, a different pair of identical objects was presented in the second encoding phase (10 min total exploration time). During the retrieval phase, two different objects, one object from each encoding phase, were placed into the apparatus and animals were given $10 \mathrm{~min}$ to explore them.

All behavior was video recorded and analyzed automatically by software (ANY-maze, version 4.99, Stoelting Co., Wood Dale, IL). The distance travelled, time spent in the central zone and in the peripheral zone were measured for the open field test. The object exploration was defined as the animal approaching the object at a distance of less than 2 $\mathrm{cm}$. The animal climbing onto the object with both hind- and forelimbs was not considered as exploration. In the same trial, objects were counterbalanced, and between trials, the placements of novel and familiar objects were changed. In the recency test, the discrimination ratio was calculated as follows: [least recent object time - most recent object time]/[least object time + most recent object time] x $100 \%$. To increase the reliability of behavioral assessment, the recency test was performed twice with new pairs of objects and the mean values per animal (exploration times and discrimination ratio) were used for statistical analysis. Results are expressed as the mean + SEM. SigmaPlot 13.0 and GraphPad 7 (La Jolla, CA, USA) software were used for data analysis and presentation.

\subsection{Statistical analysis}

The data are presented as mean and standard deviation (SD) or standard error of the mean (SEM) of at least three independent experiments. SigmaPlot (Systat Software Inc., Chicago, IL, USA) or GraphPad Prism version 7.00 for Windows (GraphPad Software, La Jolla California
USA) were used for statistical evaluation. Unless it is stated otherwise, pair-wise datasets were tested for significant differences using Student's $t$-test or Mann-Whitney test after testing Gaussian distribution by D'Agostino-Pearson ombinus normality test. Group-wise datasets were compared using one-way analysis of variance (ANOVA) followed by Bonferroni's post hoc test. Statistical analysis of pTau immunostainings was done with unpaired $t$-test with Welch's correction. Differences between the two genotypes undergoing two different treatments were assessed by two-way repetitive measures ANOVA followed by the HolmSidak post hoc test. Indicators of significance correspond to $\mathrm{p}<0.05$ (*), $\mathrm{p}<0.01{ }^{(* *)}$ ), and $\mathrm{p}<0.001(* * *)$.

\section{Results}

\subsection{Constitutive 5-HT7R activity induces Tau hyperphosphorylation}

The ability of Tau protein to bind and stabilize MTs is regulated by its phosphorylation at defined serine, threonine, and tyrosine residues. An increase in phosphorylation results in reduced MT binding capacity and destabilization of the MT network. To investigate a possible link between 5-HT7R-mediated signaling and Tau phosphorylation, neuroblastoma N1E-115 cells were co-transfected with vectors that carried sequences for a hemagglutinin (HA)-tagged 5-HT7R and an enhanced green fluorescent protein (eGFP)-tagged human Tau[R406W] mutant. This mutant is associated with inherited forms of FTDP-17 and facilitates Tau aggregation (Goedert and Jakes, 2005). Tau phosphorylation was determined with the phospho-specific (Thr181) antibody, AT270. This choice is supported by recent studies in which Tau phosphorylated at threonine 181 has been successfully evaluated as a noninvasive diagnostic and prognostic biomarker to screen for tau pathology associated with AD and FTLD (Janelidze et al., 2020; Thijssen et al., 2020). As shown in Fig. 1, co-expression of 5-HT7R with Tau[R406W] resulted in pronounced Tau hyperphosphorylation (Fig. 1B), which was accompanied by an increase in the amount of total Tau (Fig. 1C). Interestingly, Thr181 phosphorylation was not further enhanced by receptor stimulation with serotonin, which suggested that the 5-HT7R constitutive activity evoked a maximal response. The role of constitutive receptor activity was further supported by the observation that application of the highly selective 5-HT7R inverse agonist, SB-269970 (Lovell et al., 2000), prevented both receptor-induced Tau accumulation and hyperphosphorylation (Fig. 1B and C, Supplementary Fig. 1A-C). A possible effect of 5-HT7R overexpression on the expression levels of Tau was excluded by the observation, that both exogenous as well as endogenous Tau mRNA levels were not affected in the presence of the 5-HT7R (Supplementary Fig. 1G and H). In addition to the Thr181 epitope, we tested other phosphorylation sites involved in Tau pathology, including Ser199, Ser202, Thr205, and Ser396. In these experiments we obtained a pronounced increase of Tau[R406W] phosphorylation at Ser199, Ser202 and Thr205 in cells co-expressing 5-HT7R, while phosphorylation of S396 was not affected (Supplementary Fig. 1A-D).

Of note, co-expression of 5-HT7R together with (eGFP)-tagged human Tau wild-type (WT) also resulted in pronounced hyperphosphorylation at Thr181, which was accompanied by an increase in the amount of total Tau (Supplementary Fig. 2A and F). In order to prove a more general role of 5-HT7R in Tau pathology, we analyzed an additional human Tau mutation Tau[P301L], which is the most common mutation linked to FTLD (Hutton et al., 1998). Similarly to Tau wild-type and Tau[R406W] mutant, co-expression of Tau[P301L] and 5-HT7R led to a significant increase of Tau accumulation and phosphorylation at Thr181 (Supplementary Fig. 3A and F).

Interestingly, sites of 5-HT7R-mediated phosphorylation did not completely overlap in human wild-type (WT) Tau and Tau[P301L] mutant. In wild-type Tau, we obtained receptor-induced hyperphosphorylation at Thr181 and Ser199, but not at Ser202, Thr205 and Ser396 (Supplementary Fig. 2A-E). In case of Tau [P301L], co-expression of 5-HT7R resulted in hyperphosphorylation at Thr181, Ser199, Ser202 
A

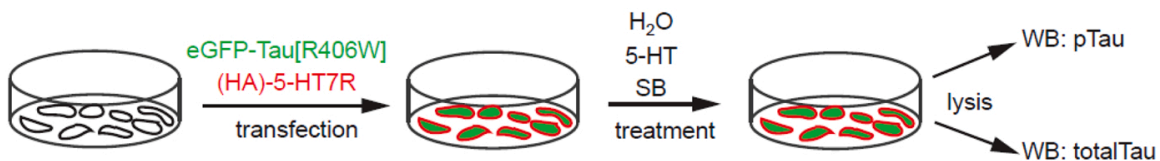

B
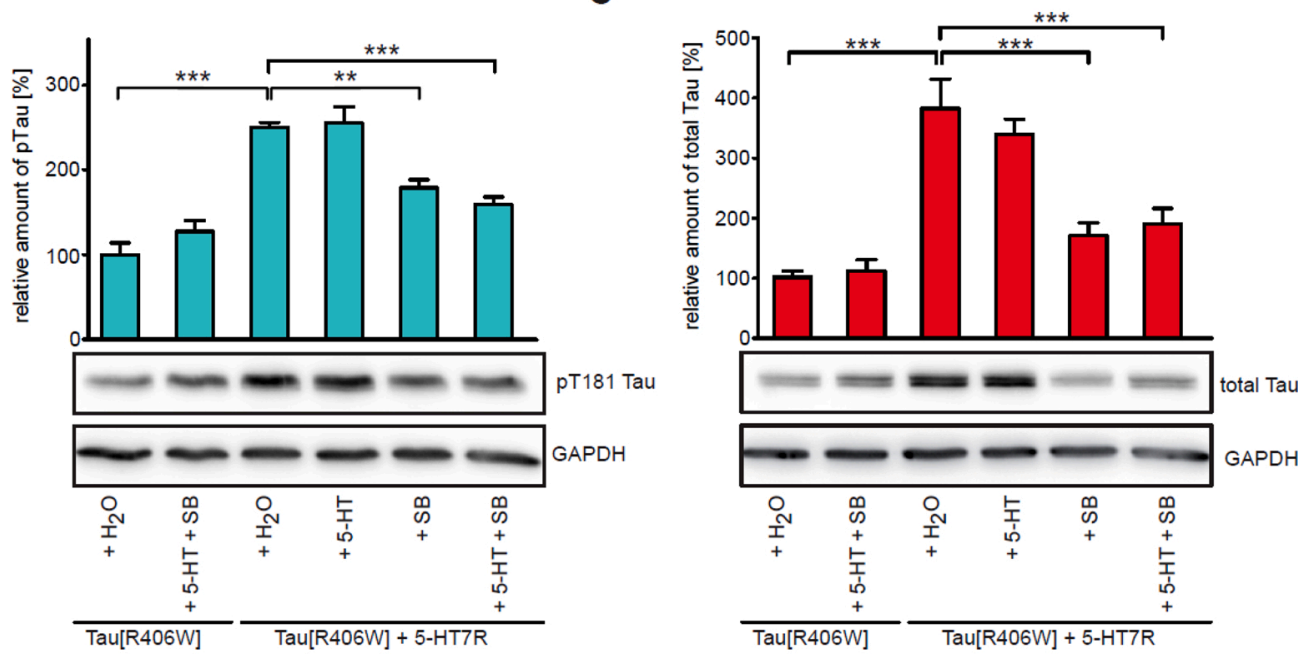

D

E

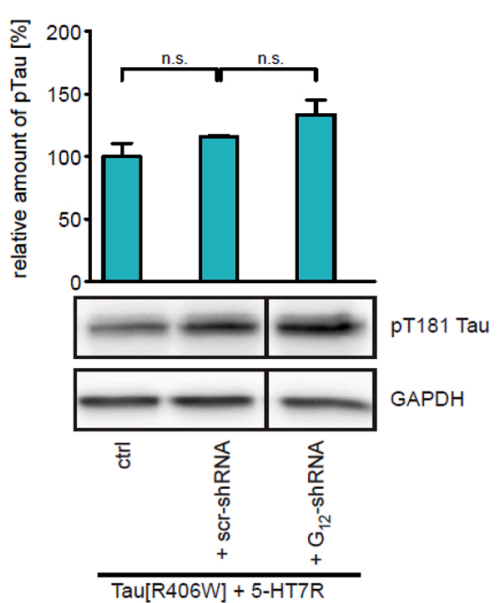

and Ser396, but not at Thr205 (Supplementary Fig. 3A-E). This is in line with previous observations showing increased CDK5-mediated phosphorylation of Ser202 in Tau[R406W] and Tau[P301L] mutants in comparison to the WT Tau (Han et al., 2009). This work also demonstrated that phosphorylation of PHF1 epitope containing Ser396 and Ser404 in Tau [P301L] mutant was higher as in the WT, while phosphorylation of these sites in Tau[R406W] was lower. In general, this data set suggests that 5-HT7R-mediated hyperphosphorylation of Ser202 in FTDP-17 associated missense mutation might play an important role in the development of pathological Tau properties. In all cases, the role of the constitutive receptor activity was confirmed by the observation that application of the 5-HT7R inverse agonist, SB-269970, prevented hyperphosphorylation and Tau accumulation (Supplementary Figs. 1-3).

We also investigated an impact of other serotonin receptors known to be involved in neurodegeneration, including 5-HT1AR, 5-HT2R and 5HT6R, on receptor-induced Tau hyperphosphorylation. Results of these experiments confirmed that constitutive 5-HT7R activity significantly facilitates phosphorylation and accumulation of Tau[R406W], while coexpression of all others tested receptors did not result in any changes in
Fig. 1. 5-HT7R induces Tau hyperphosphorylation and accumulation in a $\mathrm{G}$ protein-independent manner.

A. Experimental scheme for analyzing 5-HT7R-mediated eGFP-Tau[R406W] phosphorylation and accumulation.

B and C. Neuroblastoma N1E-115 cells were transfected with eGFP-Tau [R406W] mutant, alone or together with (HA)5-HT7R, and treated with $\mathrm{H}_{2} \mathrm{O}, 20 \mu \mathrm{M}$ 5-HT, 100 nM SB-269970, or $20 \mu \mathrm{M}$ 5-HT $+100 \mathrm{nM}$ SB-269970. Membranes were probed with (B) the phospho-specific pThr181 Tau antibody, AT270 or (C) the 5A6 antibody for assessing total Tau levels. Results were normalized to GAPDH expression and represented as the mean $+\mathrm{SD}$. Water-treated cells were set as $100 \%$ (N $=5$ ). Representative Western blots and corresponding quantifications are shown.

D and E. N1E-115 cells were cotransfected with eGFP-Tau[R406W] mutant and HA-5-HT7R, together with either a pcDNA control (ctrl), scrambled shRNA (scr-shRNA), or a specific shRNA directed against the $\mathrm{G} \alpha 12$ subunit $\left(\mathrm{G}_{12^{-}}\right.$ shRNA, see also Supplementary Fig. 1). Membranes were probed with either (D) AT270 or (E) 5A6. Results were normalized to GAPDH expression. The level of Tau phosphorylation or Tau accumulation in cells that co-expressed eGFP-Tau[R406W] and HA-5-HT7R was set to $100 \%$. Values represent the mean $+\mathrm{SD}(\mathrm{N}=3)$. Representative Western blots and corresponding quantifications are shown. $* * \mathrm{p}<0.01, * * * \mathrm{p}$ $<0.001$ (one-way ANOVA)
Tau phosphorylation and accumulation (Supplementary Fig. 1E and F).

We previously demonstrated that 5-HT7R was coupled to the heterotrimeric G12 protein (Kvachnina, 2005b). Because G12 protein is known to activate the Tau kinase, glycogen synthase kinase 3 beta (GSK3ß) (Sayas et al., 2002), we next analyzed whether 5-HT7R/G12 signaling might be involved in receptor-induced Tau hyperphosphorylation. To this end, we used short hairpin RNAs (shRNAs) to silence the endogenously expressed Go12 subunit (Supplementary Fig. $1 \mathrm{I}$ and J). Surprisingly, knocking down G $\alpha 12$ expression did not affect 5-HT7R-induced Tau phosphorylation or Tau accumulation (Fig. 1D and E) suggesting that 5-HT7R acted independently of G12 and GSK3 $\beta$.

\subsection{5-HT7R-induced Tau hyperphosphorylation is mediated by CDK5}

In addition to GSK3 $\beta$, cyclin-dependent kinase 5 (CDK5) can modulate Tau phosphorylation, and CDK5 is thought to be critically involved in AD pathogenesis (Hooper et al., 2008; Wang et al., 2013). GSK3 $\beta$ and CDK5 recognize multiple phosphorylation sites within Tau and are both known to phosphorylate Thr181 (Liu et al., 2002; Lund et al., 2001). To 
investigate whether these kinases played a role in 5-HT7R-induced Tau hyperphosphorylation, N1E-115 cells that expressed eGFP-Tau [R406W], alone or together with 5-HT7R, were treated overnight with either a selective CDK5 inhibitor, roscovitine $(20 \mu \mathrm{M})$, or a selective GSK3 $\beta$ inhibitor, SB-216763 $(10 \mu \mathrm{M})$. Consistent with previous studies, pharmacological inhibition of GSK3 $\beta$ in the absence of 5-HT7R reduced both Tau phosphorylation and total Tau levels (Fig. 2A and B) (Llorens-Martin et al., 2014; Stamos et al., 2014). However, GSK3 $\beta$ inhibition did not affect the 5-HT7R-mediated increase in Tau phosphorylation and accumulation (Fig. 2A and B), which suggested that Tau-related 5HT7R signaling was GSK3 $\beta$-independent. With roscovitine treatment, we also observed reduced levels of basal Tau phosphorylation and levels in cells that expressed eGFP-Tau[R406W] alone. However, in contrast to the results obtained with the GSK3ß inhibitor, inhibition of CDK5 using roscovitine completely abolished both 5-HT7R-mediated Tau hyperphosphorylation and the increase in total Tau levels (Fig. 2A and B). To evaluate the role of CDK5 further, we used the dominant-negative CDK5-K33T mutant and compared phosphorylation and accumulation levels of Tau between cells co-expressing 5-HT7R with Tau[R406W] and cells co-expressing 5-HT7R and Tau[R406W] together with CDK5-K33T.
A

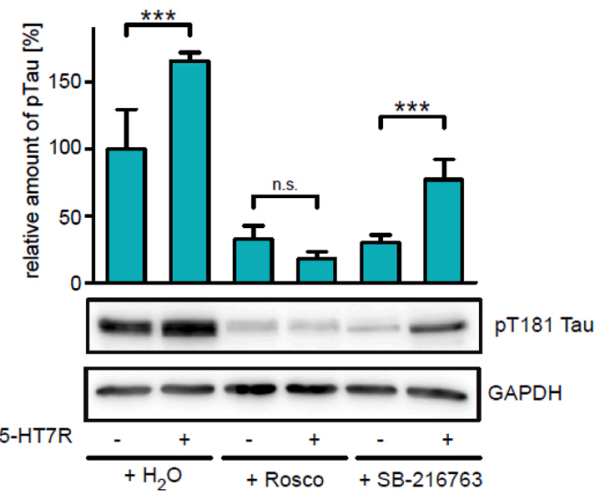

C

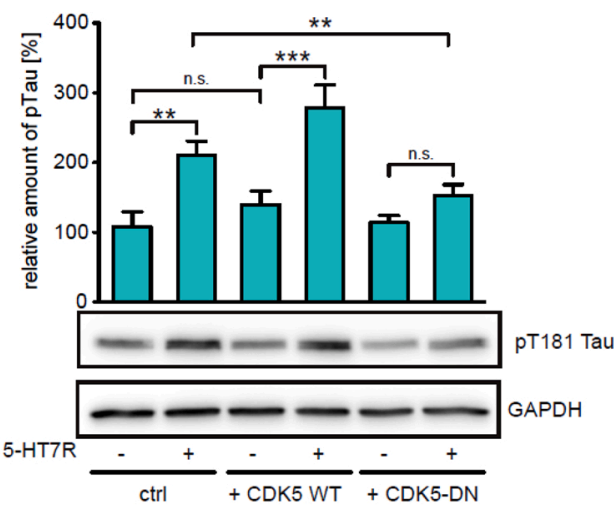

E

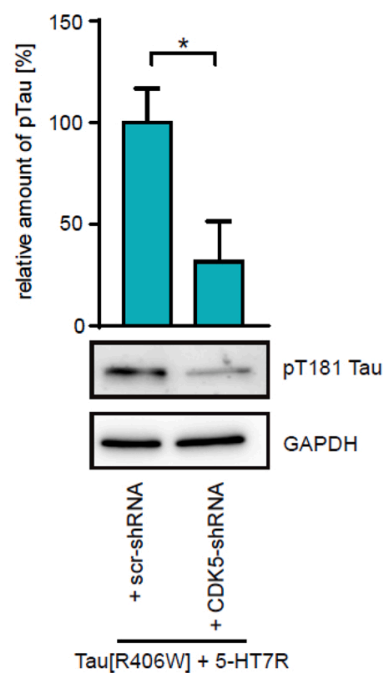

B

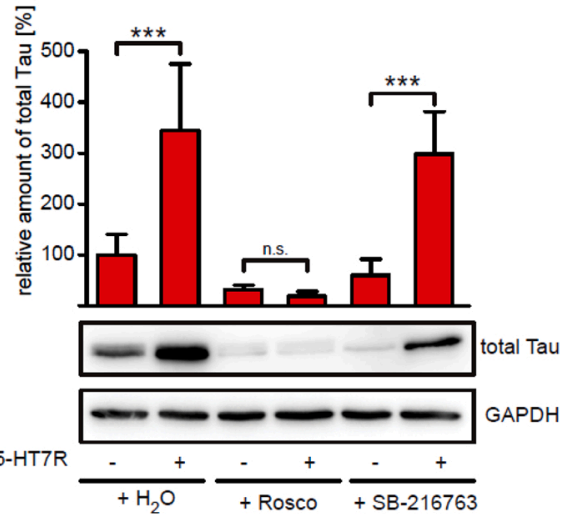

D

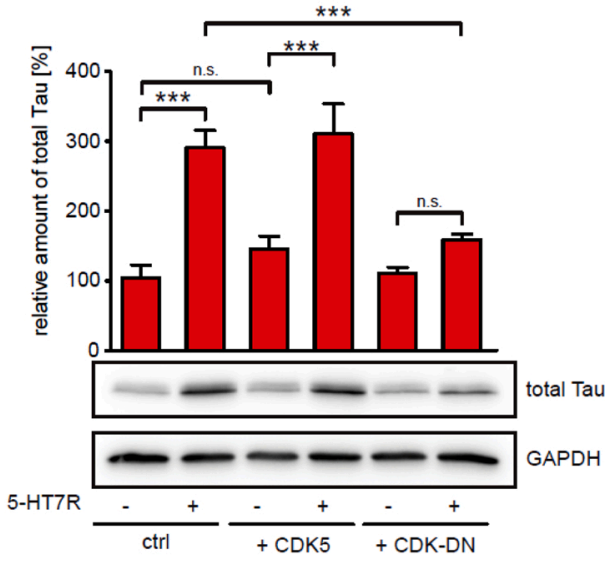

$\mathbf{F}$

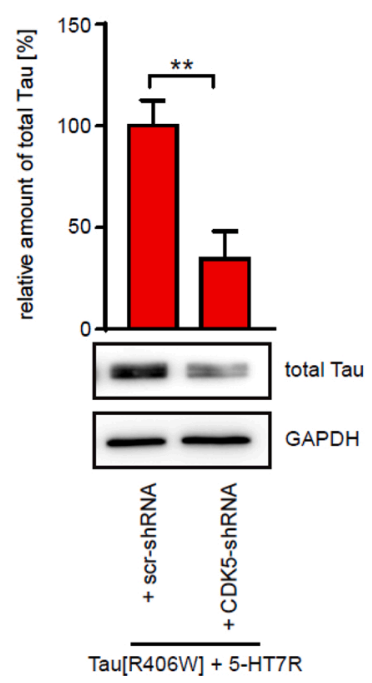

Fig. 2. 5-HT7R-induced increase in Tau phosphorylation and accumulation is mediated by CDK5, but not GSK3 $\beta$.

A and B. N1E-115 cells co-transfected with the eGFP-Tau[R406W] mutant and HA-5-HT7R were treated overnight with $20 \mu \mathrm{M}$ of the CDK5 inhibitor, roscovitine (Rosco), or $10 \mu \mathrm{M}$ of the GSK3 $\beta$ inhibitor, SB-216763. Membranes were probed with (A) the phospho-specific pTh181 Tau antibody, AT270, or (B) the anti-Tau antibody, $5 \mathrm{A6}$, for assessing total levels of Tau. Results were normalized to GAPDH expression and represent the mean $+\mathrm{SD}$ $(\mathrm{N}=4)$. Representative Western blots and quantifications are shown.

C and D. N1E-115 cells were cotransfected with plasmids that encoded HA-5-HT7R and WT CDK5-mCherry (CDK5) or the dominant negative mutant, CDK5-K33T-mCherry (CDK5DN). Membranes were probed with (C) the AT270 antibody and (D) the antiTau 5A6 antibody. Results were normalized to GAPDH expression and represent the mean $+\mathrm{SD}(\mathrm{N}=6) .{ }^{*} \mathrm{p}<$ $0.01, * * * \mathrm{p}<0.001$ (one-way ANOVA). E and F. N1E-115 cells were cotransfected with eGFP-Tau[R406W] mutant and HA-5-HT7R, together with either a scrambled shRNA (scr-shRNA), or a specific shRNA directed against the CDK5 (CDK5-shRNA, see also Supplementary Fig. S4). Membranes were probed with either (E) AT270 or (F) 5A6 antibodies. Tau expression was normalized to GAPDH expression. The level of Tau phosphorylation or accumulation in cells that co-expressed scr-shRNA was set to $100 \%$. Values represent the mean $+\mathrm{SD}(\mathrm{N}=3)$. Representative Western blots and corresponding quantifications are shown. *p $<0.05,{ }^{* *} \mathrm{p}<0.01$ (student's $t$-test). 
Quantitative analysis of these groups revealed that co-expression of CDK5-K33 T results in a significant decrease of Tau phosphorylation and accumulation (Fig. 2C and D). Similar to results obtained after pharmacological CDK5 inhibition and after overexpression of the CDK5-K33T mutant, knock-down of CDK5 by specific shRNA (Supplementary Fig. 4) in cells co-expressing 5-HT7R and eGFP-Tau[R406W] abolished the 5-HT7R-mediated effects on Tau phosphorylation and accumulation (Fig. 2E and F). Collectively, these results indicated that the observed increases in Tau phosphorylation and total Tau levels in the presence of 5-HT7R were mediated by a G12 protein-independent, 5 -HT7R-induced activation of CDK5, rather than by GSK3 $\beta$.

\subsection{5-HT7R physically interacts with CDK5}

CDK5 is known to form complexes with several neurotransmitter receptors (Duhret al., 2014; Su and Tsai, 2011). Therefore, we next investigated whether the above described signaling involved physical interactions between 5-HT7Rs and CDK5. We performed co-immunoprecipitation (co-IP) experiments in neuroblastoma N1E-115 cells that co-expressed HA-tagged 5-HT7R (HA-5-HT7R) and mCherry-tagged CDK5 (CDK5-mCherry). The results showed that CDK5 interacted with 5-HT7R (Fig. 3A). The specificity of the co-IP reaction was confirmed by analyzing cells that expressed HA-5-HT7R alone, CDK5-mCherry alone, or a mixture of these cells, performed before lysis (Fig. 3A). Since the solubilization and concentration of proteins during the co-IP procedure can result in artificial protein aggregation (Harrison and van der Graaf, 2006), weanalyzed the interaction between 5-HT7Rs and CDK5 in living cells with a Förster resonance energy transfer (FRET)-based approach. Apparent FRET efficiencies $\left(E f_{D A}\right)$ between eCFP-labeled CDK5 (CDK5-eCFP, donor) and eYFP-labeled 5-HT7R (5-HT7R-eYFP, acceptor) were measured in living N1E-115 cells with the linear unmixing FRET (lux-FRET) method, in combination with total internal reflection fluorescence (TIRF) microscopy (Supplementary Fig. 5). TIRF microscopy is particularly well suited to analyze co-localization of 5-HT7R (which is a membrane protein) and CDK5 (which is a cytosolic protein) at the plasma membrane, because it allows to exclude a large number of fluorescently labelled CDK5 molecules located outside of the optical plane of interest (i.e., plasma membrane). This combined approach allowed the detection of a physical interaction between individual molecules at the plasma membrane on the nanoscale level (Wlodarczyk et al., 2008). Analysis of N1E-115 cells that co-expressed CDK5-eCFP and 5-HT7R-eYFP revealed a high $E f_{D A}$ of $13 \% \pm 2\left(\mathrm{n}_{\text {Cell }}=26\right.$; Fig. $3 \mathrm{~B}$ and $\mathrm{C}$ ), compared to negative control cells that co-expressed eCFP and 5-HT7R-eYFP $\left(E f_{D A}=2 \% \pm 1 \%, \mathrm{n}_{\text {Cell }}=14\right.$; Fig. $3 \mathrm{~B}$ and $\mathrm{C}$ ). As a positive control, we used 5-HT7R and 5-HT1AR proteins, which are known to form heterodimers at the plasma membrane (Renner et al., 2012). The FRET-TIRF analysis of cells that co-expressed 5-HT1A-eCFP and 5-HT7R-eYFP confirmed receptor heterodimerization $\left(E f_{D A}=10 \% \pm 1\right.$ $\%, \mathrm{n}_{\text {Cell }}=22$; Fig. $3 \mathrm{~B}$ and C). These experiments demonstrated that recombinant CDK5 and 5-HT7R interacted directly and specifically at the plasma membrane. Intriguingly, this interaction occurred independently of constitutive5-HT7R activity, because when weapplied the5-HT7R inverse agonist, SB-269970, the FRET efficiency was unaffected $\left(E f_{D A}=14 \% \pm 2 \%\right.$, $\mathrm{n}_{\text {Cell }}=$ 33; Fig. 3B and C).

\subsection{5-HT7R causes Tau aggregation and partial dissociation from the microtubules in neuroblastoma cells}

To analyze whether the receptor-mediated Tau hyperphosphorylation increased Tau aggregation (a characteristic of all tauopathies), we first performed sarkosyl fractionation, an approach developed for the biochemical detection of insoluble Tau aggregates (Greenberg and Davies, 1990; Ren and Sahara, 2013). As shown in Fig. 4A and B, expression of the eGFP-Tau[R406W] mutant in the presence of the 5-HT7R led to an increase in sarkosyl-insoluble Tau, which resembled its higher-order oligomers and aggregates. Consistent with the results presented in Fig. 1, receptor stimulation with 5-HT did not promote further Tau aggregation, but treatment with the inverse agonist, SB-269970, significantly reduced the amount of insoluble Tau aggregates (Fig. 4A and B, Supplementary Fig. 6A).

To investigate whether the increased amount of insoluble Tau aggregates obtained in biochemical experiments correlates with the accumulation of Tau within the cell, we overexpressed eGFP-Tau [R406W] in N1E-115 cells and analyzed Tau localization by confocal microscopy. We found that upon 5-HT7R co-expression eGFP-Tau [R406W] is accumulated in prominent bundled structures (Supplementary Fig. 6B). To investigate whether the formation of these highly bundled Tau structures (HBTS) is accompanied by pathological dissociation of Tau from MTs, we performed co-localization analysis of eGFPtagged Tau[R406W] and MT using $\alpha$-tubulin antibody. In nontransfected neuroblastoma cells, we obtained a typical MT distribution with the essentially radial MT array focused on the centrosome, which was juxtaposed to the nuclear surface (Fig. 4C). The majority of N1E-115 cells expressing Tau[R406W] in the absence of 5-HT7R displayed a similar MT distribution with an additional enrichment of broad MT bands at the cell periphery (Fig. 4C, Supplementary Fig. 6B). More importantly, eGFP-Tau[R406W] was mostly co-localized with MT, confirming previous observations (Sahara et al., 2000). By contrast, the majority of 5-HT7R co-expressing cells was readily distinguishable by the sparse network of randomly arranged MTs accompanied by the enrichment of bundled MTs at the cell periphery (Fig. 4C). The quantitative co-localization analysis using Manders coefficient revealed that association of Tau with MT in HBTS containing cells was significantly reduced compared to cells with the regular MT organization (Fig. 4D).

For a quantitative analysis of 5-HT7R-induced formation of HBTS, we calculated the fraction of cells containing HBTS among all eGFPpositive cells. The percentage of cells with intracellular HBTS was significantly increased upon 5-HT7R co-expression (Fig. 4E). Moreover, analysis of the fluorescence intensity profiles across cells stained with the phospho-specific Tau antibody, AT8, revealed that eGFP-Tau [R406W] was overlaid with phosphorylated Tau only in cells that coexpressed the 5-HT7R, but not in cells that expressed the eGFP-Tau [R406W] alone (Fig. 4F). These data suggested that 5-HT7R-mediated Tau hyperphosphorylation was an important factor increasing the probability of Tau to aggregate, to dissociate from MT and to form highly bundled structures. Importantly, treating cells that co-expressed eGFP-Tau[R406W] and 5-HT7R with either SB-269970 (100 nM) or the CDK5 inhibitor, roscovitine $(20 \mu \mathrm{M})$, prevented both HBTS formation and Tau hyperphosphorylation (Fig. $4 \mathrm{E}$ and F). Similar results were obtained after co-expression of eGFP-Tau[R406W] and 5-HT7R with CDK5-K33T mutant (Supplementary Fig. 6C and D). Of note, overexpression of CDK5 either alone or together with 5-HT7R does not increase the percentage of cells containing HBTS (Supplementary Fig. 6C and D). Taken together, these results demonstrated the importance of 5HT7R/CDK5-mediated signaling in Tau hyperphosphorylation, Tau aggregation, and the formation of Tau bundles.

\subsection{5-HT7R/CDK5 signaling regulates Tau phosphorylation in primary cortical neurons}

To investigate the impact of 5-HT7R on Tau phosphorylation in neurons, we established primary cultures of cortical neurons isolated from WT and 5-HT7R-deficient mice. We chose cortical neurons as a model, because FTLD is characterized by preferential aggregation of pathological Tau and neuronal atrophy within the frontal and temporal cortices. With the phospho-specific Thr181 antibody, we demonstrated that the phosphorylation levels of endogenously expressed Tau were significantly lower in 5-HT7R knock-out (KO) neurons, compared to WT neurons, but the total Tau levels were similar between both groups (Fig. 5A and B). Furthermore, treating WT neurons with the inverse receptor agonist, SB-269970, or with the CDK5 inhibitor, roscovitine, resulted in significantly reduced levels of phosphorylated Tau (Fig. 5C), but these treatments did not influence the total Tau levels (Fig. 5D). These results demonstrated that 5-HT7R/CDK5 signaling was involved 
A

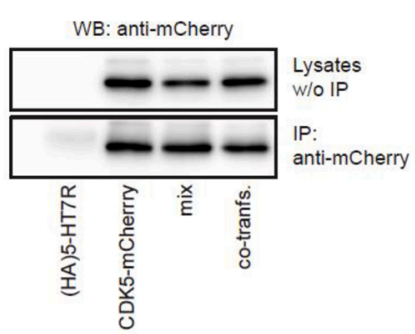

B

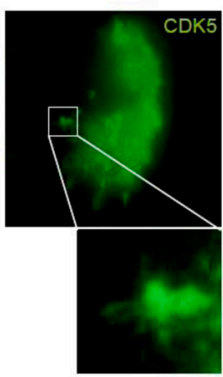

TIRF Immunofluorescence
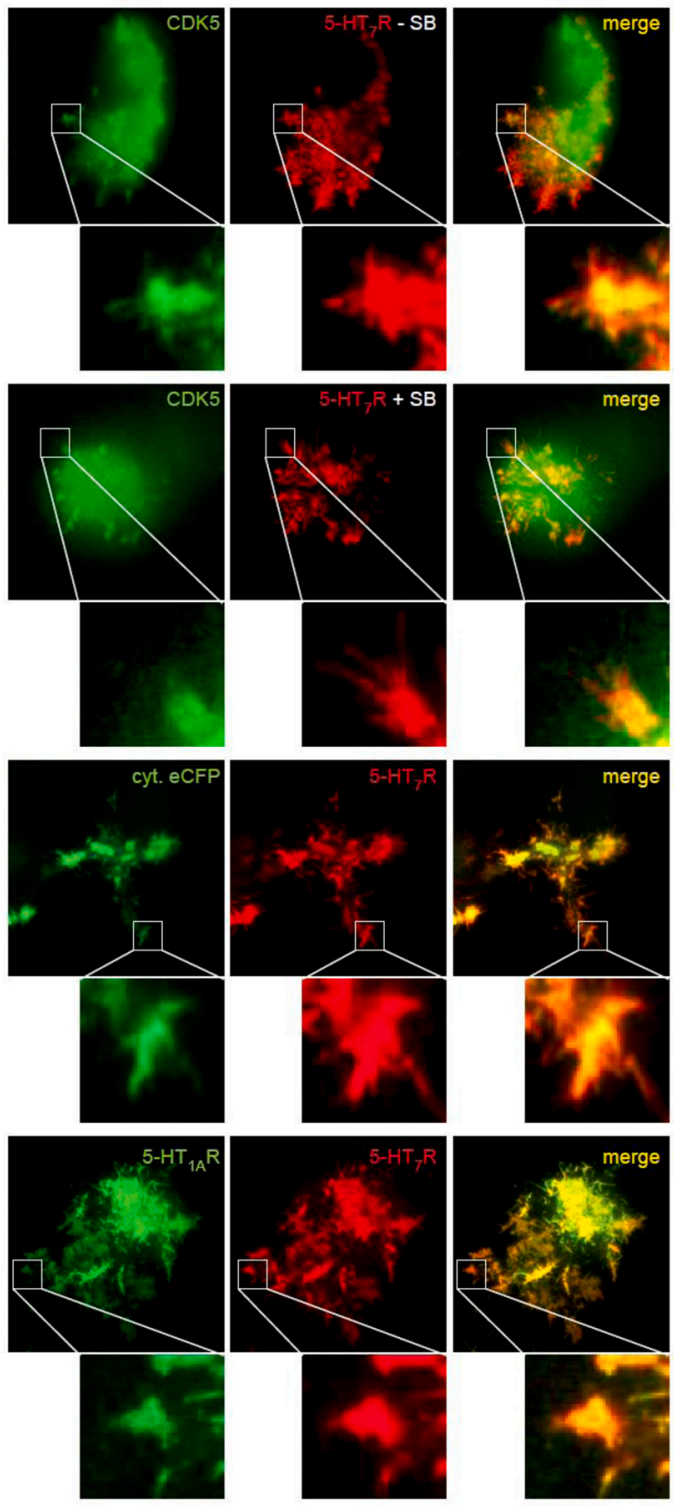

WB: anti-HA

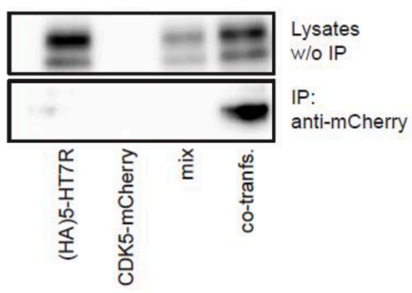

TIRF
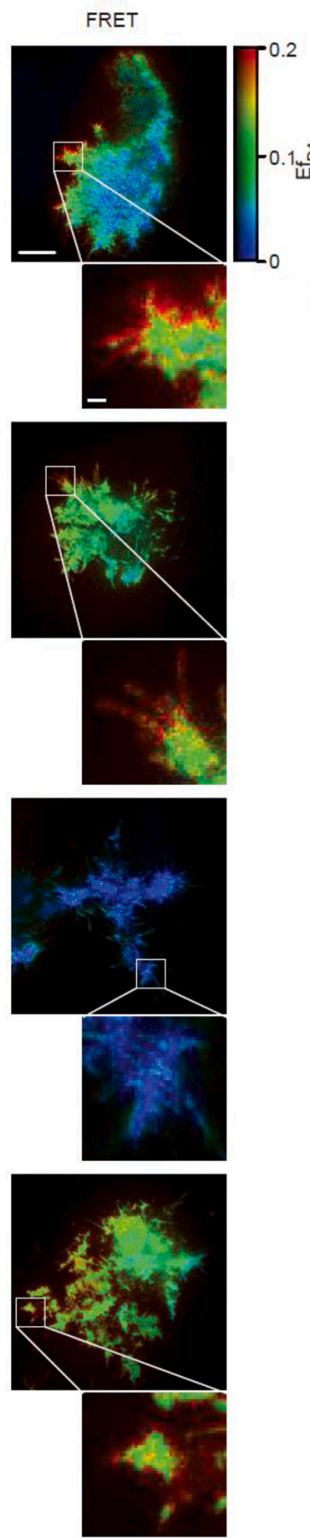

\section{C}

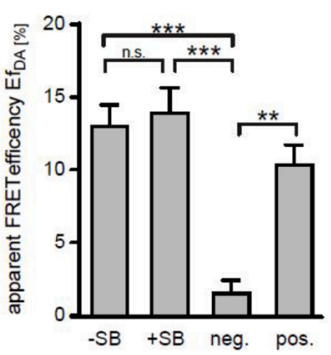

Fig. 3. Interaction between 5-HT7R and CDK5 at the plasma membrane in neuroblastoma N1E-115 cells.

A. N1E-115 cells that overexpressed either HA-5-HT7R or CDK5-mCherry alone, a mixture of cells that individually expressed either HA-5-HT7R or CDK5-mCherry (mix), and cells that coexpressed HA-5-HT7R and CDK5mCherry (co-transfection) were subjected to immunoprecipitation (IP) with anti-mCherry antibody. Next, a Western blot (WB) was performed with either an anti-mCherry or an anti-HA antibody. Inputs (lysates without IP) were assessed in parallel with the same antibodies. A representative Western blot is shown $(\mathrm{N}=4)$.

B. Representative images of N1E-115 cells transfected with CDK5-eCFP and 5-HT7R-eYFP. Images were acquired with Total Internal Reflection Fluorescence (TIRF) microscopy (Three left panels). Co-localization of CDK5 and 5HT7R at the plasma membrane; (right panel) apparent FRET efficiencies $\left(\mathrm{Ef}_{\mathrm{DA}}\right)$. Scale bar: $10 \mu \mathrm{m}$. Magnification of defined regions of interest is shown below. Scale bar: $1 \mu \mathrm{m}$. See also Supplementary Fig. 5.

C. Quantification of the apparent FRET efficiencies $\left(E f_{D A}\right)$. Transfected neuroblastoma cells were treated with $(+\mathrm{SB})$ or without (- SB) $100 \mathrm{nM} \mathrm{SB}-269970$ overnight. Cells co-transfected with cytosolic eCFP and 5-HT7R-eYFP were used as a negative control (neg). Cells that co-expressed 5-HT1AR-eCFP and 5HT7R-eYFP served as a positive control (pos). Results are the mean + SEM $(\mathrm{N}=$ 3; total analyzed cells were: $14 \leq \mathrm{n} \leq$ 33). **p $<0.01 ; * * * \mathrm{p}<0.001$ (one-way ANOVA)

in Tau phosphorylation in primary cortical neurons. Importantly, Thr181 may also be phosphorylated in fetal and adult brains under nonpathological conditions (Goedert et al., 1994). Therefore, we assume that Thr181 phosphorylation of endogenous Tau obtained in cortical neuronal cultures from WT and 5-HT7R KO mice (Fig. 5A-D) corresponds to the physiological level of Tau phosphorylation.

Based on our finding that the recombinant 5-HT7R and CDK5 physically interacted in neuroblastoma cells, we next explored whether endogenous 5-HT7R and CDK5 also interacted to form a protein complex in primary cortical neurons. An interaction between 5-HT7R and CDK5 at the cellular level was verified with immunofluorescence analyses, where primary neuron cultures were probed with antibodies directed against the 5-HT7R, CDK5, and VGLUT1, a presynaptic marker (Beaudoin et al., 2012; Ménard et al., 2015). Confocal microscopy analysis revealed that the 5-HT7R and CDK5 were co-localized at individual synapses (Fig. 5E). Co-localization of endogenous 5-HT7R and CDK5 was further confirmed in situ in cortical slices prepared from mouse brain on postnatal day 6 (P6, Fig. 5F). Finally, we performed co-IP in whole brain lysates prepared from P6 WT mice. These experiments confirmed that endogenous CDK5 interacted with the 5-HT7R in vivo (Fig. 5G). 
A

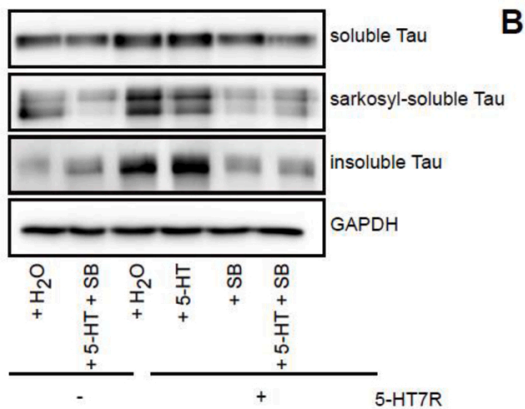

C
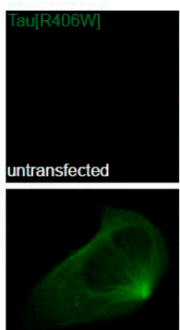

pcDNA + Tau[R406W

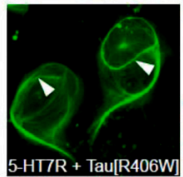

E
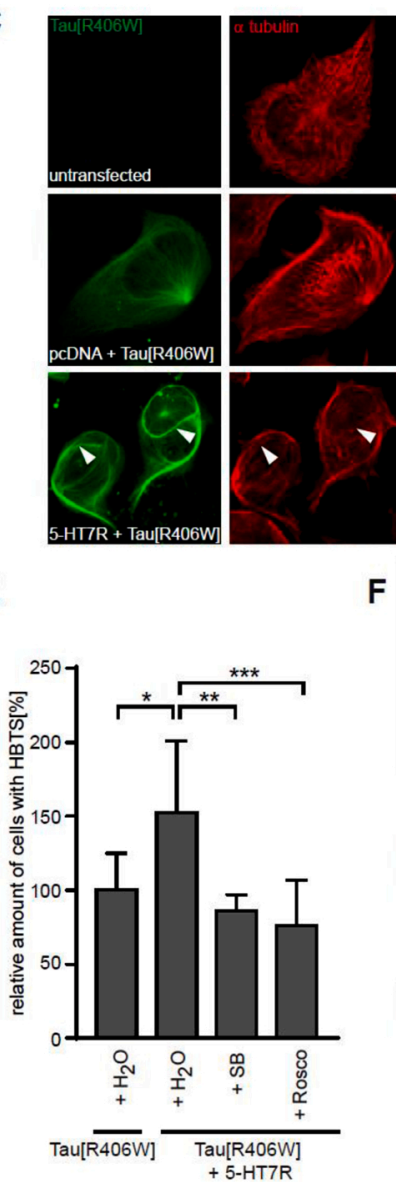

F
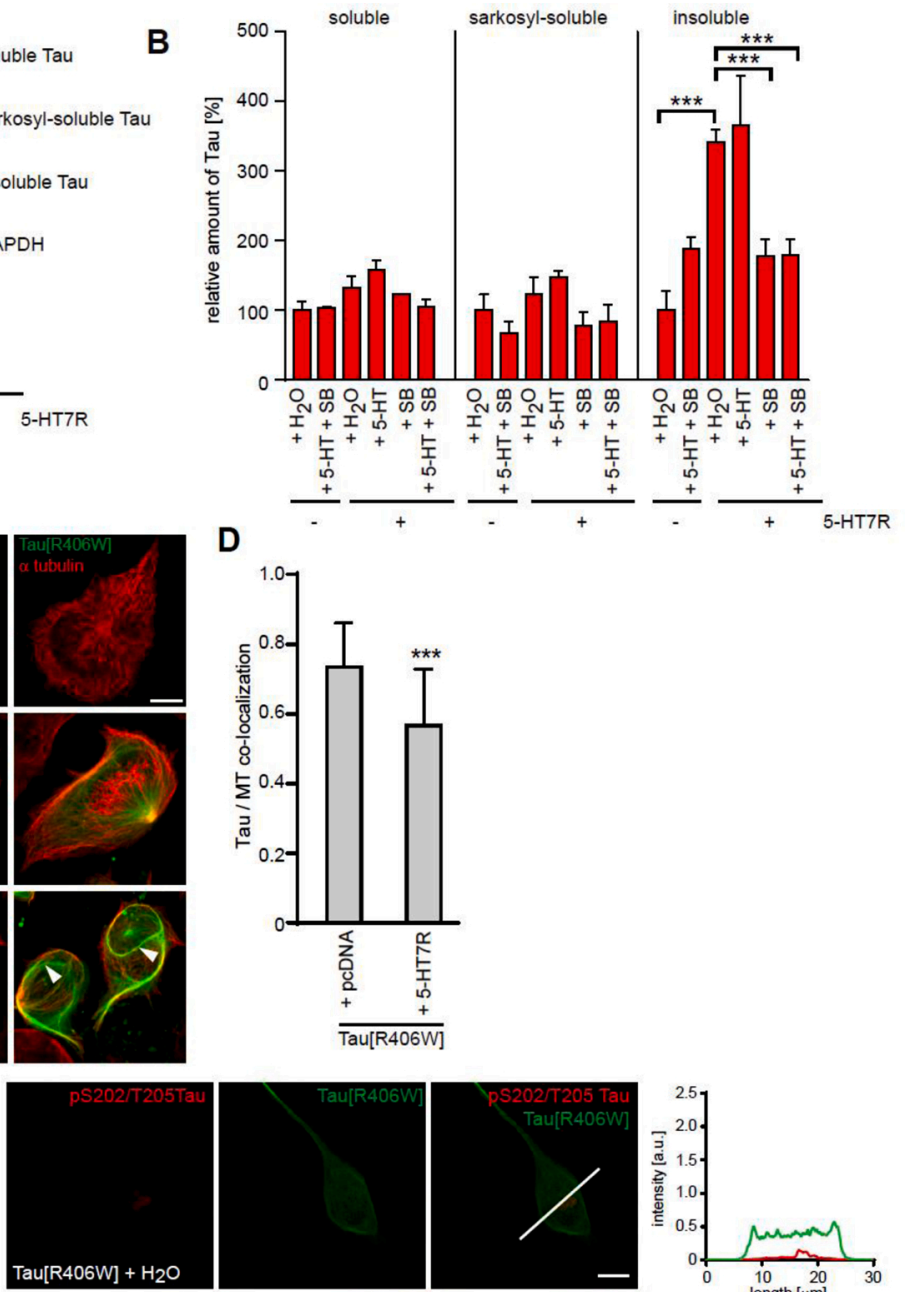

D
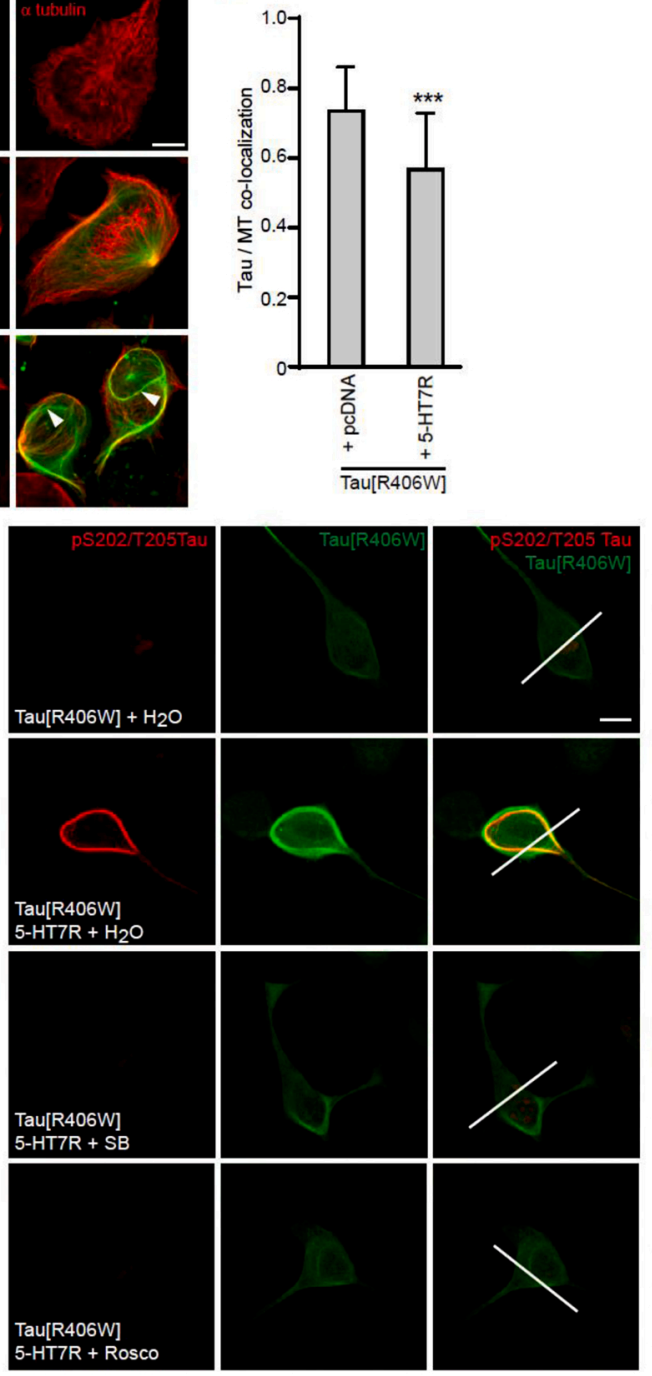

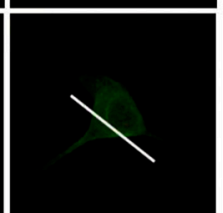

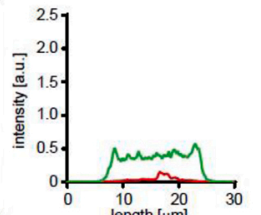
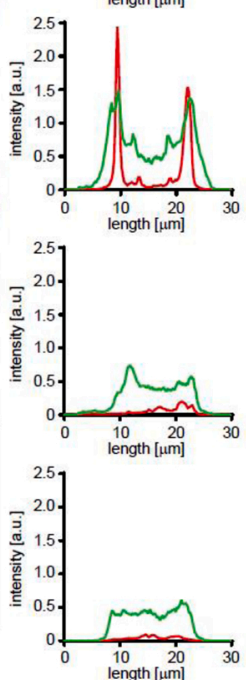

Fig. 4. Constitutive 5-HT7R activity induces Tau aggregation and formation of highly bundled Tau structures in neuroblastoma cells.

A. Representative Western blots of sarkosyl fractionation. Neuroblastoma N1E-115 cells were co-transfected with the eGFP-Tau[R406W] mutant and either pcDNA or HA-5-HT7R, and treated as indicated (SB: 5-HT7R inverse agonist SB-269970). HRP-conjugated anti-GFP antibody was used to detect total Tau levels in the soluble, sarkosylsoluble and insoluble fractions. GAPDH antibody was used as loading control of lysates.

B. Quantification of sarkosyl fractionation. Values obtained for watertreated, eGFP-Tau[R406W] mutanttransfected cells were set as $100 \%$ for each fraction. Results are the mean + SD $(\mathrm{N}=3) .{ }^{* * *} \mathrm{p}<0.001$ (one-way ANOVA).

C. Co-localization of Tau and MT in neuroblastoma cells. Untransfected N1E-115 as well as cells co-transfected with the eGFP-Tau[R406W] mutant (green) and either pcDNA or HA-5HT7R were stained with an $\alpha$ tubulin antibody (red). Representative images are shown. Scale bar: $10 \mu \mathrm{m}$. Arrowheads indicate HBTS that do not colocalize with the MT network. See also Supplementary Fig. 6B.

D. Quantitative analysis of Tau and MT co-localization in N1E-115 cells coexpressing eGFP-Tau[R406W] and either pcDNA and 5-HT7R using Manders M1 coefficient. Results are the mean + SD $(28 \leq \mathrm{N} \leq 31$, unpaired $t$ test, $* * * \mathrm{p}<0.001)$.

E. Quantification of highly bundled Tau structures (HBTS) in N1E-115 cells upon treatment. Cells were co-transfected with the eGFP-Tau[R406W] mutant and either pcDNA or HA-5-HT7R, and treated overnight with $100 \mathrm{nM} 5$-HT7R inverse agonist SB-269970 (SB) or 20 $\mu \mathrm{M}$ roscovitine. The percentage of cells with eGFP-Tau-positive HBTS was calculated based on all eGFP-Tau positive cells in a confined area $(\mathrm{N}=7$ independent experiments; total number of analyzed cells was: $2343 \leq \mathrm{n} \leq 2,799$. See also Supplementary Fig. S6B). Percentage of cells with HBTS in the control group (water-treated, transfected with eGFP-Tau[R406W] and pcDNA) was set as $100 \%$. Experiments were performed in a double-blind fashion. *p $<0.05, * * \mathrm{p}<0.01 ; * * * \mathrm{p}<0.001$ (oneway ANOVA).

F. N1E-115 cells were co-transfected with the eGFP-Tau[R406W] mutant and HA-5-HT7R, treated overnight with $100 \mathrm{nM}$ SB-269970 (SB) or $20 \mu \mathrm{M}$ roscovitine (Rosco) and stained with phospho-specific pSer202/pThr205 Tau antibody, AT8. Representative images are shown. Corresponding fluorescence intensity profiles display localization of eGFP-Tau[R406W] mutant (eGFP, 
green) and Tau phosphorylated at Ser202 and Thr 205 (AT8, red) within individual cells. Scale bar: $10 \mu \mathrm{m}$.
A

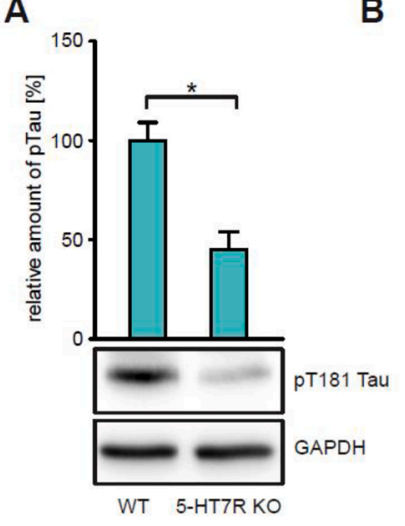

D

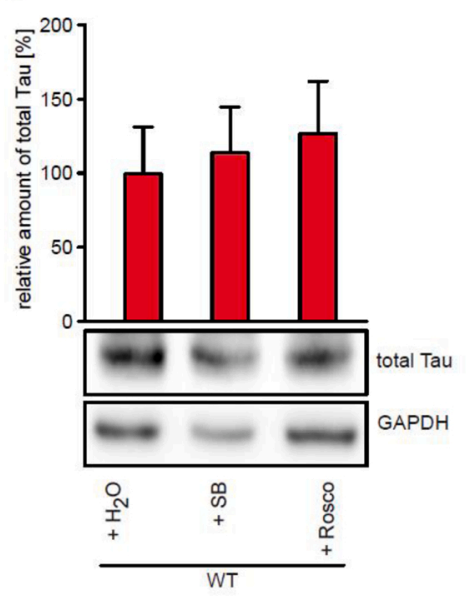

$\mathbf{F}$
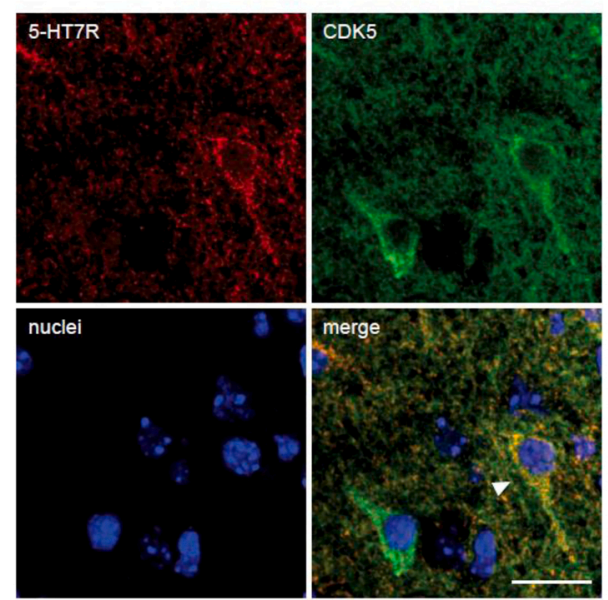

E
C
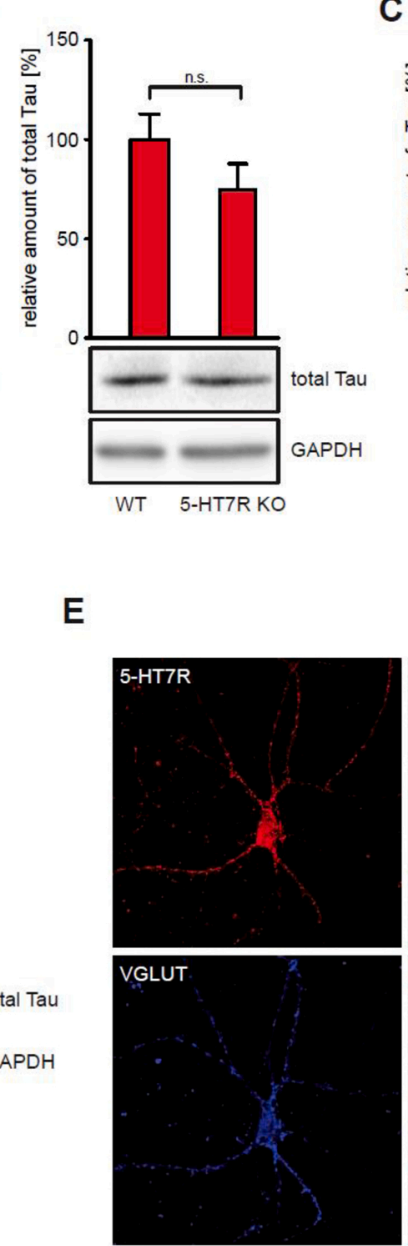

G
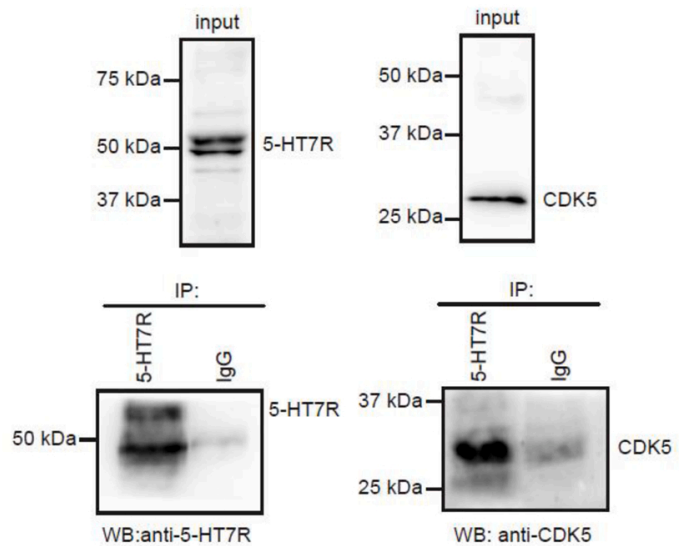

Fig. 5. Tau phosphorylation in cortical neurons is regulated by 5 -HT7R and CDK5.

A and B. Representative Western blots and corresponding quantifications show phosphorylation and expression of endogenous Tau in cultured primary cortical neurons isolated from WT or 5HT7R-KO mice at DIV 4. (A) Tau phosphorylated at Thr 181 was detected with the AT270 antibody; (B) total Tau levels were detected with the Tau-5 antibody. Results were normalized to GAPDH expression. Results are the mean + SD. ${ }^{*} \mathrm{p}<0.05$; n.s. not significantly different ( $\mathrm{N}=4$, student's $t$-test). C and D. Western blot and quantification show the phosphorylation and expression of endogenous Tau in cultured primary cortical neurons from WT mice, after overnight treatment with $100 \mathrm{nM}$ 5-HT7R inverse agonist SB-269970 (SB), $20 \mu \mathrm{M}$ roscovitine (Rosco), or $\mathrm{H}_{2} 0$. Blots were probed with (C) AT270 antibody and (D) the Tau-5 antibody. Results were normalized to GAPDH expression and represent the mean + SD. * $\mathrm{p}<0.05(\mathrm{~N}=3$, one-way ANOVA).

E. Primary cortical neurons isolated from WT mice were stained at DIV14 with antibodies against 5HT7R, CDK5, and VGLUT. Scale bar: $20 \mu \mathrm{m}$. Whiteboxed area is magnified in the lower panels. Scale bar: $2 \mu \mathrm{m}$. Arrowheads indicate co-localization.

F. Cortical slices prepared from WT mice at P6 were stained with antibodies against 5-HT7R and CDK5. Nuclei are shown in blue. Arrow heads indicate colocalization. Scale bar: $20 \mu \mathrm{m}$.

G. Co-immunoprecipitation of 5-HT7R and CDK5 from brain lysates. Whole brain homogenates were prepared from P6 mice and subjected to immunoprecipitation (IP) with the anti-5-HT7R antibody or with IgG (control), followed by Western blot (WB) analysis. Western blots were probed with anti-5HT7R and anti-CDK5 antibodies. A representative Western blot is shown ( N $=4)$.
3.6. Inhibition of 5-HT7R/CDK5 signaling reduces HBTS formation and apoptosis in neurons overexpressing Tau[R406W] mutant

We next investigated the role of 5-HT7R in HBTS formation in primary cultures of cortical neurons. We infected these cultures with an adeno-associated virus (AAV) that carried the eGFP-Tau[R406W] mutant gene (Supplementary Fig. 8A). Similar to the results obtained in neuroblastoma N1E cells, overexpression of Tau[R406W] induced the formation of HBTS (Fig. 6A) in an approximately 20 percent of neurons. Importantly, the MT network within the cell somata was largerly 
A
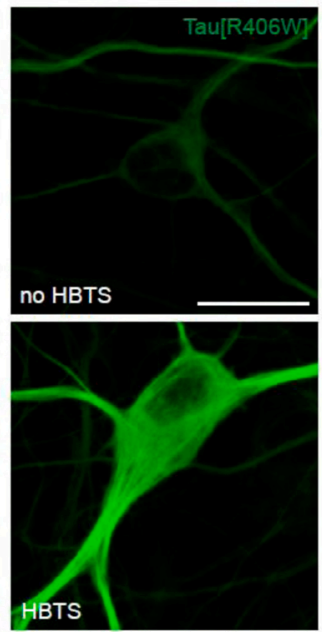

D
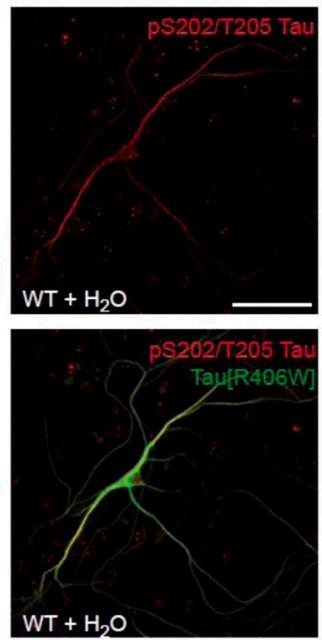

E
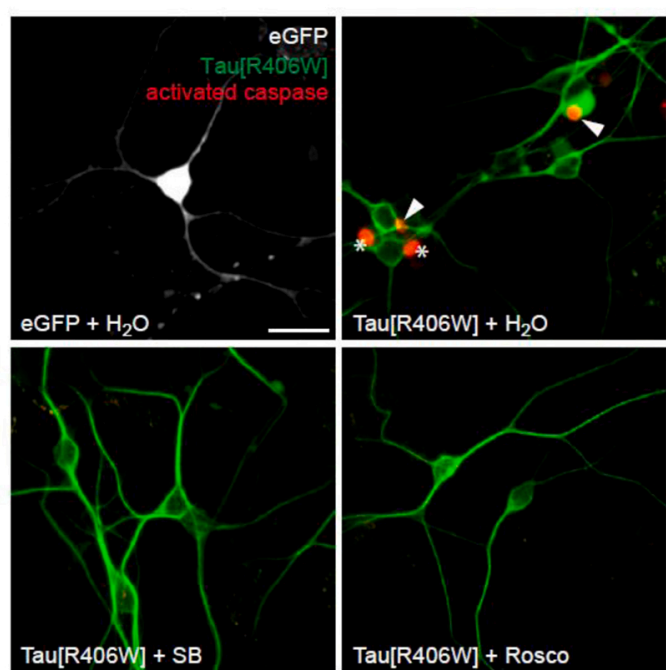

Tau[R406W] $+\mathrm{H}_{2} \mathrm{O}$

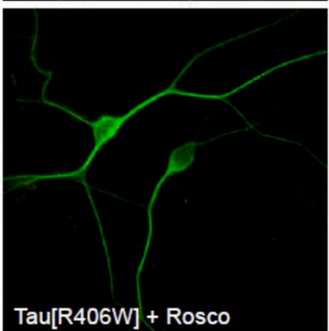

B
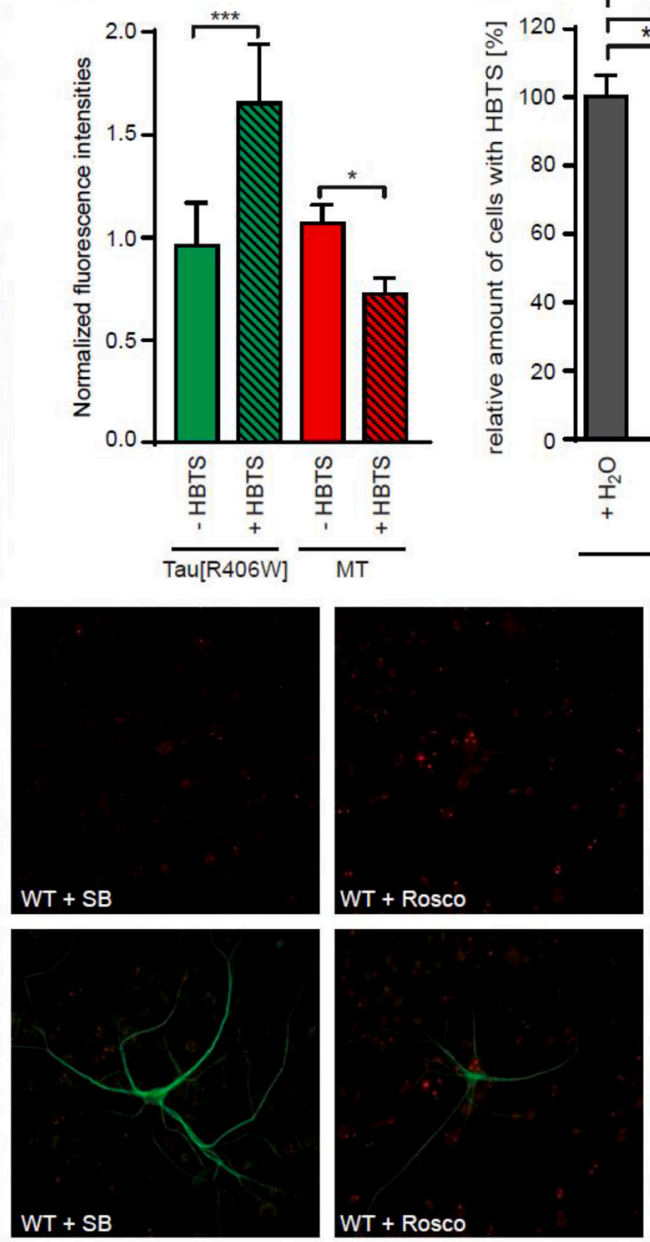

WT + Rosco
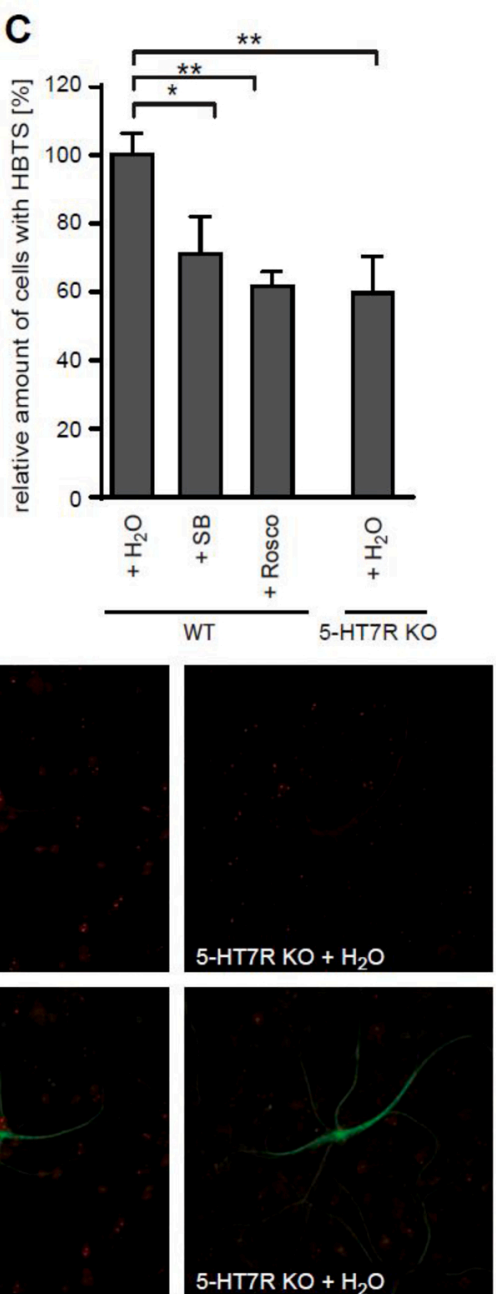

$\mathbf{F}$

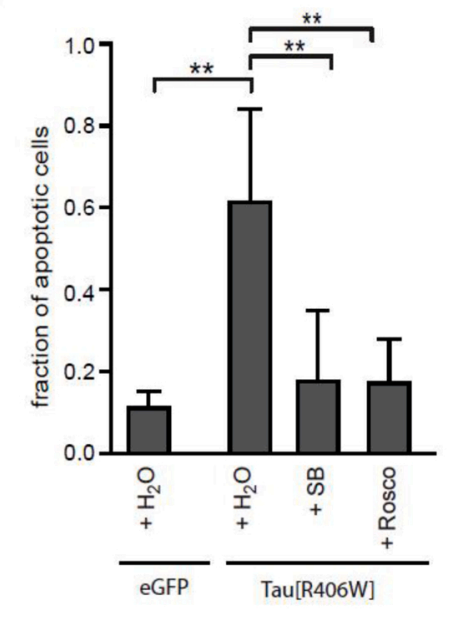

Fig. 6. Overexpression of the eGFP-Tau [R406W] mutant in cortical neurons leads to the formation of HBTS, Tau hyperphosphorylation, and increased apoptosis.

A. Representative images of primary cortical neurons with and without HBTS. Neurons were infected at DIV10 with the AAV construct that encoded the eGFP-Tau[R406W] mutant and analyzed three days post-infection. Scale bar: $20 \mu \mathrm{m}$.

B. Normalized fluorescence intensities of eGFP-Tau[R406W] (Tau, green) and $\beta$ III tubulin (MT, red) in primary cortical neurons with and without HBTS. Results are the median + interquartile range $(9 \leq \mathrm{N} \leq 12$, Mann Whitney test, *p $<0.05$; ***p $<0.001)$. See also Supplementary Fig. 7A.

C. Primary cortical neurons isolated from WT or 5-HT7R-KO mice were infected at DIV10 with the AAV-eGFPTau[R406W] mutant and treated with $\mathrm{H}_{2} \mathrm{O}, 100 \mathrm{nM}$ SB-269970 (SB), or $20 \mu \mathrm{M}$ roscovitine (Rosco) for three days, followed by imaging analysis. The number of HBTS-positive neurons is shown as the fraction of the total number of infected neurons. *p $<0.05 ;{ }^{* *} \mathrm{p}<0.01$ $(\mathrm{N}=6$; total number of analyzed cells was: $355 \leq \mathrm{n} \leq 897$, one-way ANOVA). D. Representative images of primary cortical neurons isolated from WT and 5-HT7R-KO mice, infected at DIV10 with AAV-eGFP-Tau[R406W], and treated as indicated. Expression of Tau [R406W] was visualized at DIV14 with eGFP imaging (green). Tau phosphorylation was visualized by staining with phospho-specific pSer202/pThr205 Tau antibody, AT8 (pTau, red). Scale bar: 50 $\mu \mathrm{m}$.

E. Visualization of apoptotic cells in primary cortical WT neurons infected at DIV10 with AAV constructs that encoded either eGFP alone (white) or eGFPTau[R406W] (green). Fluorescence from the cleaved substrate of active caspase3/7 indicates apoptosis (red). Arrow heads indicate cells with high caspase 3/7 activity in the nucleus. Asterisks indicate neurons with caspase3/ 7-positive exosomes. Scale bar: $20 \mu \mathrm{m}$. F. Apoptotic cells with caspase $3 / 7$ activity are shown as the fraction of the total number of infected neurons. Data are the mean $+\mathrm{SD} . * * \mathrm{p}<0.01(\mathrm{~N}=6$; total number of analyzed cells was: 123 $\leq \mathrm{n} \leq 409$, one-way ANOVA). destroyed in neurons with HBTS compared to neurons that do not show HBTS formation after Tau[R406W] expression (Supplementary Fig. 7A). Quantitative analysis of the median intensities of eGFP-Tau[R406W] and the neuron-specific $\beta$ III tubulin revealed that in HBTS-positive neurons Tau is accumulated while the expression of $\beta$ III tubulin is significantly decreased (Fig. 6B). When WT neurons were treated with the inverse receptor agonist, SB-269970 $(100 \mathrm{nM})$, or with the CDK5 inhibitor, roscovitine $(20 \mu \mathrm{M})$, the fraction of neurons with HBTS was significantly reduced, compared to vehicle-treated neurons (Fig. 6C, vehicle: $100 \% \pm 16 \%$; roscovitine: $62 \% \pm 4 \%$; SB: $71 \% \pm 11 \%$ ). Also the sarkosyl fractionation revealed reduced levels of insoluble Tau in WT neurons treated with SB-269970 compared to the untreated WT neurons (Supplementary Fig. 7C). We also infected primary cortical neurons isolated from 5-HT7R KO mice with the AAV-eGFP-Tau[R406W]. These cultures exhibited a significant reduction in the fraction of HBTSpositive neurons compared to the fraction observed in WT neurons 
(Fig. 6C, KO: $60 \% \pm 11 \%$ ). This reduced accumulation of HBTS was accompanied by reductions in Tau phosphorylation, assessed with the phospho-specific AT8 antibody via immunostaining (Fig. 6C). These results were further confirmed by Western blot analysis, which revealed reduced phosphorylation and total Tau[R406W] levels in 5-HT7R KO neurons (Supplementary Fig. 7D). In line with the results shown in Fig. 5, we also found reduced phosphorylation of endogenous Tau in 5HT7R KO neurons, compared to WT neurons, while the total Tau levels were similar between groups (Supplementary Fig. 7E). Of note, mRNA expression levels of endogenous Tau as well as human Tau[R406W] are similar in WT and 5-HT7R KO neurons (Supplementary Fig. 7F and G). Similar to the results obtained in neuroblastoma cells (Fig. 4), we found that Tau aggregates in WT neurons were mostly composed of highly phosphorylated Tau (Fig. 6D). In contrast, blocking 5-HT7R basal activity, either pharmacologically with SB-269970 or genetically by receptor knock-down, led to a drastically reduced Tau phosphorylation. Treating WT neurons that expressed eGFP-Tau[R406W] with roscovitine also abolished Tau phosphorylation (Fig. 6C).

Tau aggregation in neurons was previously shown to correlate with increased levels of apoptosis and cell death (Berger et al., 2007; Roberson et al., 2007). To elucidate whether inhibiting 5-HT7R constitutive activity might have a neuroprotective effect, we infected primary cortical neurons with an AAV that carried the eGFP-Tau[R406W] gene, and we quantified the apoptosis rate. Apoptosis was determined by detecting active caspase-3 and 7 (Fig. 6E). Besides a nuclear localization of activated caspase-3, it has been shown that the active caspase- 3 can be released from cells via caspase-3-enriched vesicles (Böing et al., 2013). The latter is the most likely reason for caspase-3-positive extracellular vesicular structures obtained in neurons overexpressing Tau [R406W] (Fig. 6E). The fraction of apoptotic neurons dramatically increased after infection with the eGFP-Tau[R406W] AAV, compared to neurons infected with a control AAV that carried the cytosolic eGFP gene (ctrl, Fig. 6F). More importantly, treating eGFP-Tau[R406W]-expressing neurons with the 5-HT7R inverse agonist, SB-269970, or with the CDK5 inhibitor, roscovitine, reduced apoptosis to the level observed in control neurons. Taken together, these results demonstrated that Tau aggregation and Tau-mediated neurotoxicity in neurons could be prevented by inhibiting constitutive 5-HT7R activity.

\subsection{5-HT7R knockdown abrogates LTP impairment induced by overexpressing the Tau[R406W] mutant}

To investigate the effects of Tau mutant overexpression on synaptic plasticity in the medial prefrontal cortex (mPFC), we injected AAVeGFP-Tau[R406W] or control AAV-eGFP vectors into the mPFC of 2month-old C57BL/6 J mice (Fig. 7A, Supplementary Fig. 8A and C). At 4-6 weeks after the AAV injections, we recorded long-term potentiation (LTP) in the mPFCs of these mice. Field excitatory postsynaptic potential (fEPSP) recordings showed a strong reduction of LTP levels in mPFC slices from AAV-eGFP-Tau[R406W]-injected mice $(112.62 \pm 5.10 \%)$ compared to mPFC slices from AAV-eGFP-injected control mice (138.13 $\pm 5.28 \%$ ) (Fig. 7B and C). This result suggested that Tau[R406W] overexpression impaired synaptic plasticity in this brain region.

Next, we assessed whether knocking down 5-HT7R expression with a short hairpin RNA (shRNA) could restore Tau[R406W]-induced LTP deficits. We co-injected 2-month-old C57BL/6 J mice with AAV-eGFPTau[R406W] and AAV-5-HT7R-shRNA-eGFP (Fig. 7A). This treatment efficiently reduced 5-HT7R mRNA levels in cortical neurons (Supplementary Fig. 8B). As a negative control, we injected animals with a nonsense shRNA (AAV-scramble-shRNA-eGFP). We found that coinjecting mice with AAV-eGFP-Tau[R406W] and either the scramble shRNA (scr) or the 5-HT7R-shRNA caused significant increases in Tau mRNA in mouse mPFC and 5-HT7R-shRNA caused reduced receptor expression 5 weeks after injection (Supplementary Fig. 8C an D). Importantly, mice co-injected with AAV-eGFP-Tau[R406W] and AAV-5HT7R-shRNA-eGFP showed significantly higher LTP levels (145.94 \pm
7.26\%) than mice co-injected with AAV-eGFP-Tau[R406W] and AAVscramble-shRNA-eGFP (99.48 $\pm 8.43 \%$ ) (Fig. 7B and C). Immunohistochemical analysis of brain sections with rabbit anti-pTau antibodies against phospho-Thr205 and the mouse AT8 antibody against phosphoSer202 and -Thr205 confirmed that the AAV-eGFP-Tau[R406W] injection strongly upregulated Tau phosphorylation compared to the AAVeGFP injection (Fig. 7D and E, Supplementary Figs. 8E and 9). Moreover, in mice injected with AAV-eGFP-Tau[R406W], knocking down the 5-HT7R with 5-HT7R-shRNA strongly reduced Tau phosphorylation, as compared with the scrambled shRNA injection (Fig. 7D and E, Supplementary Fig. 9). Thus, our electrophysiological and immunohistochemical data suggest that a 5-HT7R knockdown specifically increases LTP to physiological levels by abrogating the pathological effects of Tau [R406W] expression.

\subsection{Knockdown of 5-HT7R rescues memory impairment induced by overexpressing the Tau[R406W] mutant in mouse brain}

Next, we assessed whether the histopathological and electrophysiological alterations observed in neuronal cultures and in situ also led to behavioral abnormalities in vivo. To that end, we injected either AAVeGFP (control) or AAV-eGFP-Tau[R406W], together with AAV-5HT7R-shRNA-eGFP or AAV-scramble-shRNA-eGFP, into the mPFC of 10 -week-old C57BL/6 J mice. Six weeks after injection, these animals were subjected to behavioral tests.

The open field test did not reveal any differences between the groups (Supplementary Fig. 8F and G). These results indicated that AAV injections into the mPFC did not influence general locomotor activity or the level of anxiety. Next, we performed a recent-object recognition test to evaluate cognitive function regulated by the mPFC (Nelson et al., 2011). In this test, a mouse could choose between two previously seen objects. Normally, animals spend less time at the most recently seen object (Fig. 7F). This was indeed the case for mice co-injected with AAV-eGFP and AAV-scramble-shRNA-eGFP (control group). These mice spent $30 \pm 3 \mathrm{~s}$ near objects seen most recently and $54 \pm 4$ s near objects seen less recently (Fig. 7F). However, mice co-injected with AAV-eGFP-Tau[R406W] and AAV-scramble-shRNA-eGFP showed impaired object recognition; these animals spent a similar amount of time near both objects ( $36 \pm 3 \mathrm{~s}$ and $42 \pm 3 \mathrm{~s}$, respectively). The preference of spending more time at the less recently seen object can also be quantified with the object discrimination index. This index was close to 0 for the AAV-eGFP-Tau[R406W] + AAV-scramble-shRNA-eGFP group, which was significantly lower than for the control group. This indicated that mPFC function was impaired, due to the overexpression of Tau [R406W]. Remarkably, mice that co-expressed eGFP-Tau[R406W] with AAV-5-HT7R-shRNA-eGFP spent significantly more time at the less recently seen object, relative to the most recently seen object $(45 \pm 4 \mathrm{~s}$ and $30+2 \mathrm{~s}$, respectively), and the value of discrimination index was restored to normal (Fig. 7F). Taken together, these results indicated that the detrimental effects of mPFC Tau[R406W] expression on memory could be prevented by knocking down 5-HT7R expression.

\section{Discussion}

In the present study, we demonstrated that the constitutive activity of 5-HT7R-induced Tau hyperphosphorylation and formation of HBTS through a G protein-independent, CDK5-dependent mechanism. This receptor-mediated CDK5 activation resulted in increased neurotoxicity, attenuated LTP, and impaired memory - hallmarks of multiple tauopathies. Blockade of the constitutive 5-HT7R activity ameliorated the pathological consequences of Tau hyperphosphorylation. These findings highlighted 5-HT7R as a previously unrecognized therapeutic target for tauopathy treatments.

During the past decade, numerous $\mathrm{G}$ protein coupled receptors have been shown to exhibit agonist-independent basal activity, whereby most classical "antagonists" seem to be inverse agonists reducing the level of 
A

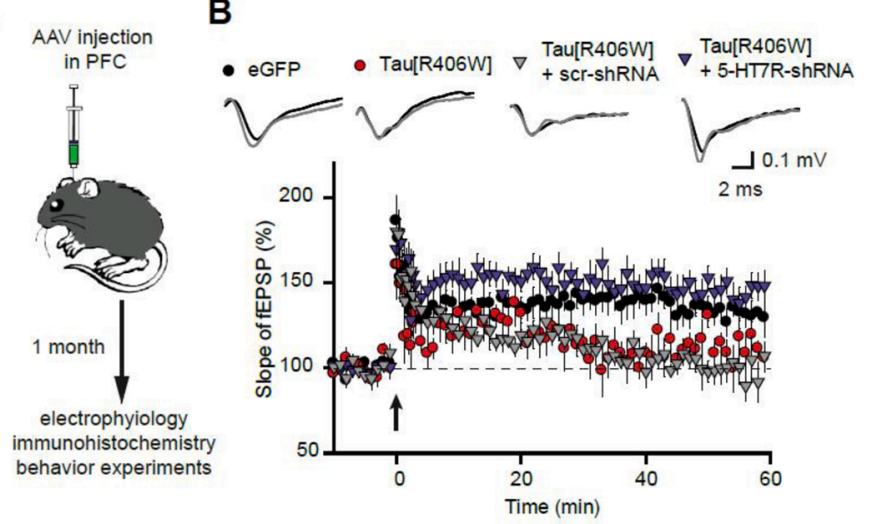

D
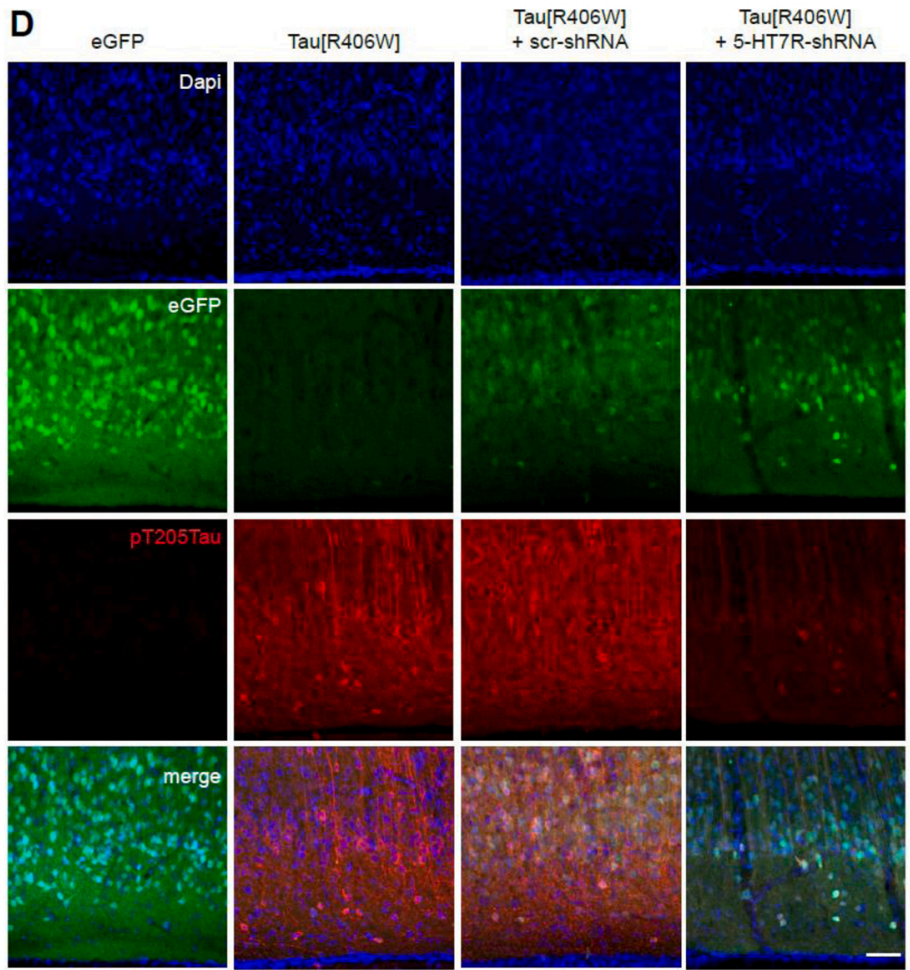

$\mathbf{F}$
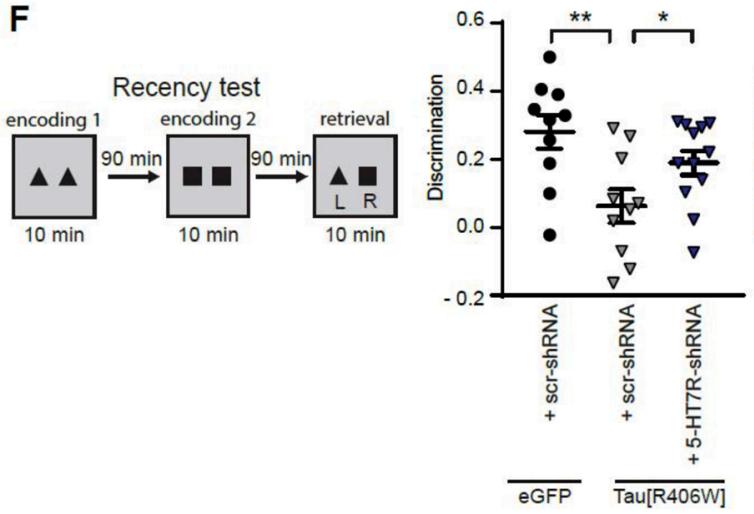

Tau[R406W] + 5-HT7R-shRNA

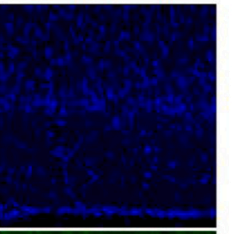

C

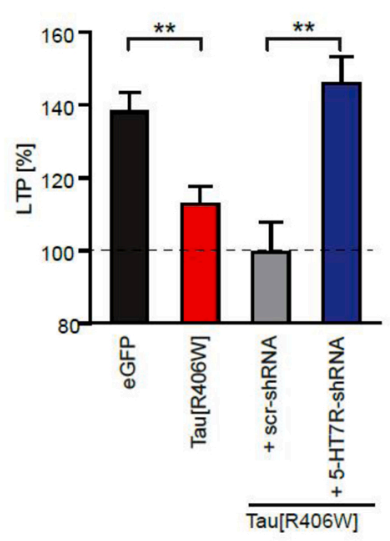

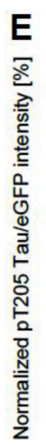
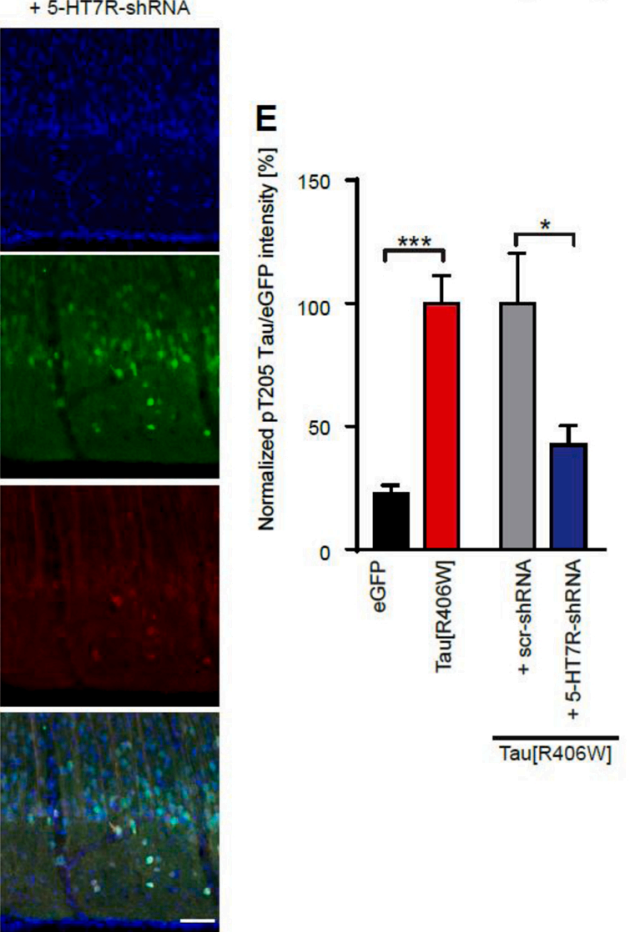

Fig. 7. 5-HT7R knockdown abrogates LTP and memory impairment induced by overexpressing Tau[R406W] mutant in the mouse mPFC.

A. Scheme shows the experimental design: different AAVs (see also Supplementary Fig. 8A) were injected stereotactically into the MPFC of WT mice. After one month, animals were subjected to analysis.

B. Normalized mean slopes and representative examples of field excitatory postsynaptic potentials (fEPSPs) in brain slices from WT mice that were injected with AAV-eGFP (black), AAVeGFP-Tau[R406W] (red), AAV-eGFPTau[R406W] + AAV-scramble-shRNA (gray), or AAV-eGFP-Tau[R406W] + AAV-5-HT7R-shRNA (purple, see also Fig. S8B). The arrow denotes the time point at which five trains of theta-burst stimulation (TBS) were applied. The insets represent averages of 30 fEPSPs recorded at 0-10 min before TBS (black, baseline) and 50-60 min after TBS (gray) in each group.

C. Quantification of mean LTP levels, recorded 50-60 min after TBS delivery in all groups. Data are the mean + SEM of 7-8 recorded slices from 5 to 6 mice per group. ${ }^{* *} \mathrm{p}<0.01$ (unpaired Student's $t$ test).

D. Representative mouse PFC sections after AAV injections, which were stained with Thr205 phospho-specific Tau rabbit antibody (see also Supplementary Fig. 8E). Scrambled and shRNA groups show comparable levels of eGFP expression, which reflects expression of both eGFP-Tau[R406W] and eGFP as a marker of shRNA expressing cells. Scale bar: $100 \mu \mathrm{m}$.

E. Quantification of the ratio between the intensities of pT205 Tau and eGFP signals to take into account the individual variability in the infection levels. Data represent the normalized mean + SEM values $(6 \leq \mathrm{N} \leq 7)$ set to be on average $100 \%$ in eGFP-Tau[R406W] and eGFP-Tau[R406W] + scramble shRNA groups. ${ }^{*} \mathrm{p}<0.05$, and $* * * \mathrm{p}<$ 0.001 (Student's $t$-test).

F. Five weeks after injecting the indicated AAVs into the PFC, mice were subjected to the recency test. Quantification shows the discrimination and exploration times spent with the less recently seen (L) and the more recently seen (R) objects. Data are the mean + SEM $(10 \leq \mathrm{N} \leq 12)$. ${ }^{*} \mathrm{p}<0.05,{ }^{* *} \mathrm{p}<$ 0.01 , and $* * * \mathrm{p}<0.001$ (one-way ANOVA).

constitutive activity below that of the unliganded receptor (Bond and IJzerman, 2006). Moreover, multiple studies have suggested that receptor constitutive activity plays an essential role in the pathogenesis of numerous diseases (Smit et al., 2007). Although human and rodent 5-HT7Rs have been shown to exhibit relatively high constitutive activity (Krobert and Levy, 2002; Romero et al., 2006), its pathophysiological role remains to be addressed. To our knowledge, the present study is the first to demonstrate the importance of constitutive 5-HT7R signaling in Tau-related neurodegeneration. The role of constitutive 5-HT7R activity in tauopathies is also consistent with the observation that the number of serotonergic projections was not affected in frontotemporal dementia, which is exclusively characterized by Tau hyperphosphorylation and 
NFT accumulation (Bowen et al., 2008). Moreover, genome-wide association studies found single-nucleotide polymorphisms located in close proximity to the 5-HT7R gene in a Dutch population of patients with late-onset AD (Liu et al., 2007). That finding suggested that mutations within the 5-HT7R gene might be etiologically relevant, at least in subpopulations of patients with $\mathrm{AD}$.

In the present study, we showed that the co-expression of 5-HT7R and the eGFP-tagged human Tau[R406W] and Tau[P301L] mutants, which are associated with inherited forms of FTDP-17 (Goedert and Jakes, 2005), caused dissociation of Tau from MT, massive Tau hyperphosphorylation and an increase in Tau levels in neuroblastoma cells. The latter finding could be explained by the possibility that already a small amount of pathologically phosphorylated Tau can act as a nucleation factor for inducing Tau aggregation (Frost et al., 2009; Guo and Lee, 2011; Nonaka et al., 2010; Sanders et al., 2014). These conditions could then lead to the inhibition of proteasomal degradation pathways, thereby reducing the cell's capacity to break down aggregated Tau (Keck et al., 2003; Opattova et al., 2013; Poppek et al., 2006; Tai et al., 2012). Receptor-mediated Tau hyperphosphorylation and accumulation was not affected by receptor stimulation with 5 -HT, but it was completely blocked by the 5-HT7R inverse agonist, SB-269970. These results demonstrated that constitutive 5-HT7R activity played a pivotal role in the hyperphosphorylation of "pathological" Tau, both in vitro and in vivo. Moreover, because both inverse agonist treatment and genetic 5-HT7R ablation significantly reduced endogenous Tau phosphorylation in cultured neurons and in the brain, it follows that the constitutive activity of the 5-HT7R must be critically involved in the phosphorylation of "physiological" Tau. This is further confirmed by the observation that co-expression of 5-HT7R together with the human WT Tau leads to increased Tau phosphorylation and aggregation, and application of the 5-HT7R inverse agonist, SB-269970, prevented these effects.

Searching for signaling mechanisms that might underlie 5-HT7Rmediated Tau hyperphosphorylation and aggregation, we identified CDK5 as a novel 5-HT7R interaction partner. We verified the interaction between 5-HT7R and CDK5 in a recombinant system, in primary neuronal cultures, and in mouse brain. These findings suggested that the 5-HT7R/CDK5 complex might be an integral part of the signaling network involved in Tau phosphorylation. Our experiments also showed that the CDK5-5-HT7R interaction was detected in the absence of any ligands, which indicated that the interaction occurred independent of the receptor conformation. Indeed, the 5-HT7R/CDK5 complex was not disrupted in the presence of an inverse agonist, which shifted the receptor isomerization from an active to an inactive form.

The 5-HT7R appeared to act as a direct upstream regulator of CDK5 activity at the plasma membrane. This was evidenced by several observations: (i) the 5-HT7R bound to CDK5 and regulated phosphorylation of its substrate, Tau; (ii) an inverse agonist produced a similar inhibitory effect on Tau phosphorylation as that obtained upon the expression of a CDK5 dominant-negative mutant; and (iii) no G12 activation was necessary for 5-HT7R-induced, CDK5-dependent Tau phosphorylation.

What mechanism might underlie 5-HT7R-mediated modulation of CDK5 activity? Typically, CDK5 targeting and activity in neurons is determined by interactions with its canonical activators, p35 and p39 (Ko et al., 2001). In mouse brain, both activators are expressed at relatively low levels and undergo region-specific and developmental regulation (Takahashi et al., 2003). Thus, we could speculate that the 5-HT7R might act as a "signaling-hub", thereby increasing the amount and/or duration of CDK5 in the plasma membrane, where p35 and p39 reside (Su and Tsai, 2011). In this scenario, a stable interaction between 5-HT7R and CDK5 could increase the probability that the kinase is in close proximity to its activators (i.e., p35 or p39). Moreover, activation of CDK5 might be further facilitated through the active conformation of the 5-HT7R. Thus, inverse agonist treatment shifted the receptor equilibrium toward the inactive conformation, which led to CDK5 inactivation without disrupting the 5-HT7R/CDK5 complex. Future studies will be needed to decipher the mechanisms of receptor-mediated CDK5 activation more precisely.

In tauopathies, like AD or FTDP-17, Tau hyperphosphorylation promotes its own accumulation and aggregation into neurotoxic NFTs (Arendt et al., 2016; Mandelkow and Mandelkow, 2012; Wang and Mandelkow, 2015). Although we explored only five of several possible phosphorylation sites on the Tau protein, Ser199, Thr181, Ser202, Thr205, and Ser396, we found that 5-HT7R-induced hyperphosphorylation of the Tau[R406W] mutant was sufficient to facilitate the formation of HBTS structures in cortical neurons and to boost neuronal apoptosis. At the systemic level, this resulted in impaired LTP and profound memory loss. More importantly, ablation of the 5-HT7R prevented CDK5-mediated Tau[R406W] hyperphosphorylation and aggregation, which led to the complete rescue of all pathological consequences of Tau [R406W] overexpression, both at the cellular and systemic levels in vivo. Similar effects were obtained with a pharmacological blockade of CDK5, which suggested a pivotal role of 5-HT7R/CDK5 module rather than canonical receptor-mediated signaling in modulating pathological Tau hyperphosphorylation. This hypothesis was further supported by the observation that cognitive performance in WT mice was not altered by either the pharmacological inhibition or a genetic knock-out of 5-HT7R (Sarkisyan and Hedlund, 2009).

In addition to its possible role in Tau phosphorylation, the 5-HT7R has been recently implicated in depression and anxiety. Multiple studies have suggested that 5-HT7R might be a relevant target for the treatments of depression (Gellynck et al., 2013). That view was supported by the finding that chronic antidepressant treatment led to reduced 5-HT7R density in rodent brains (Mullins et al., 1999). Moreover, a pharmacological blockade or knockdown of the 5-HT7R induced antidepressant-like behaviors and induced pro-cognitive effects in animal models (Guscott et al., 2005; Hedlund et al., 2005). Therefore, it might be envisioned that 5-HT7R inhibition could provide symptomatic relief in depression and cognitive decline, two major early symptoms of AD (Katz, 1998). Indeed, new antidepressants with pharmacological profiles that combined serotonin transporter blockade and 5-HT7R antagonism (e.g., vortioxetine) were recently developed (Westrich et al., 2015) or are currently undergoing clinical trials (e.g., AVN-101, ADN-1184, or JNJ-18038683 (Bonaventure et al., 2012, p.; Ivachtchenko et al., 2016; Kołaczkowski et al., 2014, p. 1184; Partyka et al., 2016)). In light of our findings, it will be interesting to evaluate the potential disease-modifying properties of these and other agents in patients with tauopathies.

\section{Author contributions}

Designed research studies: M.B., A.D., J.L., K-F.R. and E.P. Supervised experiments: M.B., A.D., J.L. and E.P. Acquired data: KF.R., J.A., H.V., F.M., S.J., R.K., K.J., A.-L.V., M.B., Y.S., D.G., K.B., M.Bi., S.CD. and J.L. Analyzed data: KF.R., J.A., H.V., R.K., K.J., A.-L.V., M.B., S.CD., A.Z. and J.L. Provided reagents: P.M., A.D. and E.P. Wrote the manuscript: KF.R., M.B., P.M., A.D., J.L. and E.P.

\section{Declaration of Competing Interest}

E.P., K.-F.R., M.B., J.L., A.D., H.V., S.J. are co-inventors in the international patent WO2020/065090 describing the targeting of 5-HT7 receptor for treatment of taoupathies.

\section{Acknowledgement}

This work was supported by Deutsche Forschungsgemeinschaft through grant PO732 and Excellence Cluster REBIRTH to E.P., and through grant LA4465 to J.L., Lobachevsky University 5-100 academic excellence program to E.P., TargetECM/BMBF funding for the TargetECM project (01EW1308B to E.P. and A.D.) and the Foundation for Polish Science (POIR.04.04.00-00-43BC/17-00 to M.Bi.). K.-F.R., J.A., K.J. and A.-L.V. received the StrucMed-Scholarship of the Hannover 
Biomedical Research School - Graduate School of Excellence and conducted the majority of their experimental contribution within the framework of this program. K-F. R. received a scholarship from the German Academic Scholarship Foundation and from the Ministry for Science and Culture of Lower Saxony We thank Tania Bunke, Dalia Abdel-Galil, Gwendolin Sabrina Simper, and Mareike Kubinski for excellent technical assistance.

\section{Appendix A. The Peer Review Overview and Supplementary data}

The Peer Review Overview and Supplementary data associated with this article can be found in the online version, at doi:https://doi.org/10 .1016/j.pneurobio.2020.101900.

\section{References}

Arendt, T., Stieler, J.T., Holzer, M., 2016. Tau and tauopathies. Brain Res. Bull. 126, 238-292. https://doi.org/10.1016/j.brainresbull.2016.08.018.

Atri, A., Frölich, L., Ballard, C., Tariot, P.N., Molinuevo, J.L., Boneva, N., Windfeld, K., Raket, L.L., Cummings, J.L., 2018. Effect of Idalopirdine as adjunct to cholinesterase inhibitors on change in cognition in patients with Alzheimer disease: three randomized clinical trials. JAMA 319, 130-142. https://doi.org/10.1001/ jama.2017.20373.

Beaudoin, G.M.J., Lee, S.-H., Singh, D., Yuan, Y., Ng, Y.-G., Reichardt, L.F., Arikkath, J. 2012. Culturing pyramidal neurons from the early postnatal mouse hippocampus and cortex. Nat. Protoc. 7, 1741-1754. https://doi.org/10.1038/nprot.2012.099.

Berger, Z., Roder, H., Hanna, A., Carlson, A., Rangachari, V., Yue, M., Wszolek, Z., Ashe, K., Knight, J., Dickson, D., Andorfer, C., Rosenberry, T.L., Lewis, J., Hutton, M., Janus, C., 2007. Accumulation of pathological tau species and memory loss in a conditional model of Tauopathy. J. Neurosci. 27, 3650-3662. https://doi. org/10.1523/JNEUROSCI.0587-07.2007.

Böing, A.N., Stap, J., Hau, C.M., Afink, G.B., Ris-Stalpers, C., Reits, E.A., Sturk, A., van Noorden, C.J.F., Nieuwland, R., 2013. Active caspase-3 is removed from cells by release of caspase-3-enriched vesicles. Biochim. Biophys. Acta BBA - Mol. Cell Res. 1833, 1844-1852. https://doi.org/10.1016/j.bbamcr.2013.03.013.

Bonaventure, P., Dugovic, C., Kramer, M., De Boer, P., Singh, J., Wilson, S., Bertelsen, K. Di, J., Shelton, J., Aluisio, L., Dvorak, L., Fraser, I., Lord, B., Nepomuceno, D., Ahnaou, A., Drinkenburg, W., Chai, W., Dvorak, C., Sands, S., Carruthers, N., Lovenberg, T.W., 2012. Translational evaluation of JNJ-18038683, a 5-hydroxytryptamine type 7 receptor antagonist, on rapid eye movement sleep and in major depressive disorder. J. Pharmacol. Exp. Ther. 342, 429-440. https://doi.org/ 10.1124/jpet.112.193995.

Bond, R.A., IJzerman, A.P., 2006. Recent developments in constitutive receptor activity and inverse agonism, and their potential for GPCR drug discovery. Trends Pharmacol. Sci. 27, 92-96. https://doi.org/10.1016/j.tips.2005.12.007.

Bowen, D.M., Procter, A.W., Mann, D.M.A., Snowden, J.S., Esiri, M.M., Neary, D., Francis, P.T., 2008. Imbalance of a serotonergic system in frontotemporal dementia: implication for pharmacotherapy. Psychopharmacology 196, 603-610. https://doi. org/10.1007/s00213-007-0992-8.

Buee, L., Bussiere, T., Buee-Scherrer, V., Delacourte, A., Hof, P.R., 2000. Tau protein isoforms, phosphorylation and role in neurodegenerative disorders. Brain Res. Brain Res. Rev. 33, 95-130 https://doi.org/S0165017300000199 [pii].

Butzlaff, M., Ponimaskin, E., 2016. The role of serotonin receptors in alzheimer's disease. Opera Med. Physiol. 91-100.

Chen, C.P.L.-H., Eastwood, S.L., Hope, T., McDonald, B., Francis, P.T., Esiri, M.M., 2000 Immunocytochemical study of the dorsal and median raphe nuclei in patients with Alzheimer's disease prospectively assessed for behavioural changes. Neuropathol. Appl. Neurobiol. 26, 347-355. https://doi.org/10.1046/j.1365-2990.2000.00254.x.

Cirrito, J.R., Disabato, B.M., Restivo, J.L., Verges, D.K., Goebel, W.D., Sathyan, A., Hayreh, D., D’Angelo, G., Benzinger, T., Yoon, H., Kim, J., Morris, J.C., Mintun, M. A., Sheline, Y.I., 2011. Serotonin signaling is associated with lower amyloid- $\beta$ levels and plaques in transgenic mice and humans. Proc. Natl. Acad. Sci. U. S. A. 108, 14968-14973. https://doi.org/10.1073/pnas.1107411108.

Clavaguera, F., Bolmont, T., Crowther, R.A., Abramowski, D., Frank, S., Probst, A. Fraser, G., Stalder, A.K., Beibel, M., Staufenbiel, M., Jucker, M., Goedert, M. Tolnay, M., 2009. Transmission and spreading of tauopathy in transgenic mouse brain. Nat. Cell Biol. 11, 909-913. https://doi.org/10.1038/ncb1901.

Cochet, M., Donneger, R., Cassier, E., Gaven, F., Lichtenthaler, S.F., Marin, P., Bockaert, J., Dumuis, A., Claeysen, S., 2013. 5-HT4 receptors constitutively promote the non-amyloidogenic pathway of APP cleavage and interact with ADAM10. ACS Chem. Neurosci. 4, 130-140. https://doi.org/10.1021/cn300095t.

Duhr, F., Déléris, P., Raynaud, F., Séveno, M., Morisset-Lopez, S., Mannoury la Cour, C., Millan, M.J., Bockaert, J., Marin, P., Chaumont-Dubel, S., 2014. Cdk5 induces constitutive activation of 5-HT6 receptors to promote neurite growth. Nat. Chem. Biol. 10, 590-597. https://doi.org/10.1038/nchembio.1547.

Duthey, B., 2013. Background Paper 6.11: Alzheimer Disease and Other Dementias. A Public Health Approach to Innovation.

Franklin, K., Paxinos, G., 2008. The Mouse Brain in Stereotaxic Coordinates, Compact, 3rd ed. [WWW Document]. URL https://www.elsevier.com/books/the-mouse-brain -in-stereotaxic-coordinates-compact/franklin/978-0-12-374244-5 (Accessed 1 February 19).

Frost, B., Jacks, R.L., Diamond, M.I., 2009. Propagation of tau misfolding from the outside to the inside of a cell. J. Biol. Chem. 284, 12845-12852. https://doi.org/ 10.1074/jbc.M808759200.

Gellynck, E., Heyninck, K., Andressen, K.W., Haegeman, G., Levy, F.O., Vanhoenacker, P., Craenenbroeck, K.V., 2013. The serotonin 5-HT7 receptors: two decades of research. Exp. Brain Res. 230, 555-568. https://doi.org/10.1007/ s00221-013-3694-y.

Goedert, M., Jakes, R., 2005. Mutations causing neurodegenerative tauopathies. Biochim. Biophys. Acta BBA - Mol. Basis Dis. 1739, 240-250. https://doi.org/ 10.1016/j.bbadis. 2004.08.007.

Goedert, M., Jakes, R., Crowther, R.A., Cohen, P., Vanmechelen, E., Vandermeeren, M., Cras, P., 1994. Epitope mapping of monoclonal antibodies to the paired helical filaments of Alzheimer's disease: identification of phosphorylation sites in tau protein. Biochem. J. 301, 871-877. https://doi.org/10.1042/bj3010871.

Gomez-Isla, T., Hollister, R., West, H., Mui, S., Growdon, J.H., Petersen, R.C., Parisi, J.E., Hyman, B.T., 1997. Neuronal loss correlates with but exceeds neurofibrillary tangles in Alzheimer's disease. Ann. Neurol. 41, 17-24. https://doi.org/10.1002/ ana.410410106.

Greenberg, S.G., Davies, P., 1990. A preparation of Alzheimer paired helical filaments that displays distinct tau proteins by polyacrylamide gel electrophoresis. Proc. Natl. Acad. Sci. U. S. A. 87, 5827-5831.

Grundke-Iqbal, I., Iqbal, K., Quinlan, M., Tung, Y.C., Zaidi, M.S., Wisniewski, H.M., 1986. Microtubule-associated protein tau. A component of Alzheimer paired helical filaments. J. Biol. Chem. 261, 6084-6089.

Guo, J.L., Lee, V.M.-Y., 2011. Seeding of normal tau by pathological tau conformers drives pathogenesis of Alzheimer-like tangles. J. Biol. Chem. 286, 15317-15331. https://doi.org/10.1074/jbc.M110.209296.

Guscott, M., Bristow, L.J., Hadingham, K., Rosahl, T.W., Beer, M.S., Stanton, J.A Bromidge, F., Owens, A.P., Huscroft, I., Myers, J., Rupniak, N.M., Patel, S., Whiting, P.J., Hutson, P.H., Fone, K.C., Biello, S.M., Kulagowski, J.J., McAllister, G., 2005. Genetic knockout and pharmacological blockade studies of the 5-HT7 receptor suggest therapeutic potential in depression. Neuropharmacology 48, 492-502. https://doi.org/10.1016/j.neuropharm.2004.11.015.

Guseva, D., Angelov, D.N., Irintchev, A., Schachner, M., 2009. Ablation of adhesion molecule L1 in mice favours Schwann cell proliferation and functional recovery after peripheral nerve injury. Brain 132, 2180-2195. https://doi.org/10.1093/brain/ awp160.

Han, D., Qureshi, H.Y., Lu, Y., Paudel, H.K., 2009. Familial FTDP-17 missense mutations inhibit microtubule assembly-promoting activity of Tau by increasing phosphorylation at Ser202 in vitro. J. Biol. Chem. 284, 13422-13433. https://doi org/10.1074/jbc.M901095200.

Harrison, C., van der Graaf, P.H., 2006. Current methods used to investigate G protein coupled receptor oligomerisation. J. Pharmacol. Toxicol. Methods 54, 26-35. https://doi.org/10.1016/j.vascn.2005.11.001.

Hedlund, P., Sutcliffe, J., 2004. Functional, molecular and pharmacological advances in 5-HT receptor research. Trends Pharmacol. Sci. 25, 481-486. https://doi.org/ 10.1016/j.tips.2004.07.002.

Hedlund, P.B., Danielson, P.E., Thomas, E.A., Slanina, K., Carson, M.J., Sutcliffe, J.G., 2003. No hypothermic response to serotonin in 5-HT7 receptor knockout mice. Proc. Natl. Acad. Sci. U. S. A. 100, 1375-1380. https://doi.org/10.1073/ pnas.0337340100.

Hedlund, P.B., Huitron-Resendiz, S., Henriksen, S.J., Sutcliffe, J.G., 2005. 5-HT7 receptor inhibition and inactivation induce antidepressantlike behavior and sleep pattern. Biol. Psychiatry 58, 831-837. https://doi.org/10.1016/j.biopsych.2005.05.012.

Hong, M., Zhukareva, V., Vogelsberg-Ragaglia, V., Wszolek, Z., Reed, L., Miller, B.I, Geschwind, D.H., Bird, T.D., McKeel, D., Goate, A., Morris, J.C., Wilhelmsen, K.C. Schellenberg, G.D., Trojanowski, J.Q., Lee, V.M.-Y., 1998. Mutation-specific functional impairments in distinct tau isoforms of hereditary FTDP-17. Science 282, 1914. https://doi.org/10.1126/science.282.5395.1914.

Hooper, C., Killick, R., Lovestone, S., 2008. The GSK3 hypothesis of Alzheimer's disease: GSK3 and Alzheimer's disease. J. Neurochem. 104, 1433-1439. https://doi.org/ 10.1111/j.1471-4159.2007.05194.x.

Hutton, M., Lendon, C.L., Rizzu, P., Baker, M., Froelich, S., Houlden, H., PickeringBrown, S., Chakraverty, S., Isaacs, A., Grover, A., Hackett, J., Adamson, J., Lincoln, S., Dickson, D., Davies, P., Petersen, R.C., Stevens, M., de Graaff, E., Wauters, E., van Baren, J., Hillebrand, M., Joosse, M., Kwon, J.M., Nowotny, P., Che, L.K., Norton, J., Morris, J.C., Reed, L.A., Trojanowski, J., Basun, H., Lannfelt, L., Neystat, M., Fahn, S., Dark, F., Tannenberg, T., Dodd, P.R., Hayward, N., Kwok, J.B. J., Schofield, P.R., Andreadis, A., Snowden, J., Craufurd, D., Neary, D., Owen, F., Oostra, B.A., Hardy, J., Goate, A., van Swieten, J., Mann, D., Lynch, T., Heutink, P. 1998. Association of missense and $5^{\prime}$-splice-site mutations in tau with the inherited dementia FTDP-17. Nature 393, 702-705. https://doi.org/10.1038/31508.

Ivachtchenko, A.V., Lavrovsky, Y., Okun, I., 2016. AVN-101: a multi-target drug candidate for the treatment of CNS disorders. J. Alzheimer's Dis. 53, 583-620. https://doi.org/10.3233/JAD-151146.

Janelidze, S., Mattsson, N., Palmqvist, S., Smith, R., Beach, T.G., Serrano, G.E., Chai, X., Proctor, N.K., Eichenlaub, U., Zetterberg, H., Blennow, K., Reiman, E.M. Stomrud, E., Dage, J.L., Hansson, O., 2020. Plasma P-tau181 in Alzheimer's disease: relationship to other biomarkers, differential diagnosis, neuropathology and longitudinal progression to Alzheimer's dementia. Nat. Med. 26, 379-386. https:// doi.org/10.1038/s41591-020-0755-1.

Jo, C., Gundemir, S., Pritchard, S., Jin, Y.N., Rahman, I., Johnson, G.V.W., 2014. Nrf2 reduces levels of phosphorylated tau protein by inducing autophagy adaptor protein NDP52. Nat. Commun. 5, 3496. https://doi.org/10.1038/ncomms4496. 
Josephs, K.A., 2017. Current understanding of neurodegenerative diseases associated with the protein tau. Mayo Clin. Proc. 92, 1291-1303. https://doi.org/10.1016/ mayocp.2017.04.016.

Katz, I.R., 1998. Diagnosis and treatment of depression in patients with Alzheimer's disease and other dementias. J. Clin. Psychiatry 59 (Suppl. 9), 38-44.

Keck, S., Nitsch, R., Grune, T., Ullrich, O., 2003. Proteasome inhibition by paired helical filament-Tau in brains of patients with Alzheimer's disease: proteasome inhibition in Alzheimer's disease. J. Neurochem. 85, 115-122. https://doi.org/10.1046/j.1471 4159.2003.01642.x.

KIDD, M., 1963. Paired helical filaments in electron microscopy of Alzheimer's disease. Nature 197, 192-193. https://doi.org/10.1038/197192b0.

Ko, J., Humbert, S., Bronson, R.T., Takahashi, S., Kulkarni, A.B., Li, E., Tsai, L.-H., 2001 p35 and p39 are essential for cyclin-dependent kinase 5 function during neurodevelopment. J. Neurosci. 21, 6758-6771. https://doi.org/10.1523/ JNEUROSCI.21-17-06758.2001.

Kobe, F., Guseva, D., Jensen, T.P., Wirth, A., Renner, U., Hess, D., Muller, M. Medrihan, L., Zhang, W., Zhang, M., Braun, K., Westerholz, S., Herzog, A., Radyushkin, K., El-Kordi, A., Ehrenreich, H., Richter, D.W., Rusakov, D.A., Ponimaskin, E., 2012. 5-HT7R/G12 signaling regulates neuronal morphology and function in an age-dependent manner. J. Neurosci. 32, 2915-2930. https://doi.org/ 10.1523/JNEUROSCI.2765-11.2012.

Kołaczkowski, M., Mierzejewski, P., Bieńkowski, P., Wesołowska, A., NewmanTancredi, A., 2014. ADN-1184 a monoaminergic ligand with 5-HT $6 / 7$ receptor antagonist activity: pharmacological profile and potential therapeutic utility: pharmacology of the monoamine antagonist ADN-1184. Br. J. Pharmacol. 171 973-984. https://doi.org/10.1111/bph.12509.

Kovacs, G.G., Klöppel, S., Fischer, I., Dorner, S., Lindeck-Pozza, E., Birner, P., Bötefür, I. C., Pilz, P., Volk, B., Budka, H., 2003. Nucleus-specific alteration of raphe neurons in human neurodegenerative disorders. Neuroreport 14, 73-76. https://doi.org/ 10.1097/01.wnr.0000050301.92401.0c.

Krobert, K.A., Levy, F.O., 2002. The human 5-HT7 serotonin receptor splice variants: constitutive activity and inverse agonist effects. Br. J. Pharmacol. 135, 1563-1571. https://doi.org/10.1038/sj.bjp.0704588.

Kvachnina, E., 2005a. 5-HT7 receptor is coupled to $g$ subunits of heterotrimeric G12 Protein to regulate gene transcription and neuronal morphology. J. Neurosci. 25 7821-7830. https://doi.org/10.1523/JNEUROSCI.1790-05.2005.

Kvachnina, E., 2005b. 5-HT7 receptor is coupled to $\mathrm{g}$ subunits of heterotrimeric G12protein to regulate gene transcription and neuronal morphology. J. Neurosci. 25, 7821-7830. https://doi.org/10.1523/JNEUROSCI.1790-05.2005.

Lee, S.-J., Lim, H.-S., Masliah, E., Lee, H.-J., 2011. Protein aggregate spreading in neurodegenerative diseases: problems and perspectives. Neurosci. Res. 70, 339-348. https://doi.org/10.1016/j.neures.2011.05.008.

Liu, F., Iqbal, K., Grundke-Iqbal, I., Gong, C.-X., 2002. Involvement of aberrant glycosylation in phosphorylation of tau by cdk5 and. FEBS Lett. 530, 209-214.

Liu, F., Arias-Vásquez, A., Sleegers, K., Aulchenko, Y.S., Kayser, M., Sanchez-Juan, P., Feng, B.-J., Bertoli-Avella, A.M., van Swieten, J., Axenovich, T.I., Heutink, P., van Broeckhoven, C., Oostra, B.A., van Duijn, C.M., 2007. A genomewide screen for lateonset Alzheimer disease in a genetically isolated dutch population. Am. J. Hum. Genet. 81, 17-31. https://doi.org/10.1086/518720.

Llorens-Martin, M., Jurado, J., Hernandez, F., Avila, J., 2014. GSK-3b, a pivotal kinase in Alzheimer disease. Front. Mol. Neurosci. 7 https://doi.org/10.3389/ fnmol.2014.00046.

Lovell, P.J., Bromidge, S.M., Dabbs, S., Duckworth, D.M., Forbes, I.T., Jennings, A.J., King, F.D., Middlemiss, D.N., Rahman, S.K., Saunders, D.V., Collin, L.L., Hagan, J.J., Riley, G.J., Thomas, D.R., 2000. A novel, potent, and selective 5-HT(7) antagonist: (R)-3-(2-(2-(4-methylpiperidin-1-yl)ethyl)pyrrolidine-1-sulfonyl) phen ol (SB269970). J. Med. Chem. 43, 342-345.

Lund, E.T., McKenna, R., Evans, D.B., Sharma, S.K., Mathews, W.R., 2001. Characterization of the in vitro phosphorylation of human tau by tau protein kinase II (cdk5/p20) using mass spectrometry. J. Neurochem. 76, 1221-1232.

Mandelkow, E.-M., Mandelkow, E., 2012. Biochemistry and cell biology of tau protein in neurofibrillary degeneration. Cold Spring Harb. Perspect. Med. 2, a006247. https:// doi.org/10.1101/cshperspect.a006247.

Manders, E.M.M., Verbeek, F.J., Aten, J.A., 1993. Measurement of co-localization of objects in dual-colour confocal images. J. Microsc. 169, 375-382. https://doi.org/ 10.1111/j.1365-2818.1993.tb03313.x.

Ménard, C., Quirion, R., Vigneault, E., Bouchard, S., Ferland, G., El Mestikawy, S., Gaudreau, P., 2015. Glutamate presynaptic vesicular transporter and postsynaptic receptor levels correlate with spatial memory status in aging rat models. Neurobiol. Aging 36, 1471-1482. https://doi.org/10.1016/j.neurobiolaging.2014.11.013.

Minge, D., Senkov, O., Kaushik, R., Herde, M.K., Tikhobrazova, O., Wulff, A.B., Mironov, A., van Kuppevelt, T.H., Oosterhof, A., Kochlamazashvili, G., Dityatev, A., Henneberger, C., 2017. Heparan sulfates support pyramidal cell excitability, synaptic plasticity, and context discrimination. Cereb. Cortex 27, 903-918. https:// doi.org/10.1093/cercor/bhx003.

Mullins, U.L., Gianutsos, G., Eison, A.S., 1999. Effects of antidepressants on 5-HT7 receptor regulation in the rat hypothalamus. Neuropsychopharmacology 21 , 352-367. https://doi.org/10.1016/S0893-133X(99)00041-X.

Nelson, A.J.D., Cooper, M.T., Thur, K.E., Marsden, C.A., Cassaday, H.J., 2011. The effect of catecholaminergic depletion within the prelimbic and infralimbic medial prefrontal cortex on recognition memory for recency, location, and objects. Behav. Neurosci. 125, 396-403. https://doi.org/10.1037/a0023337.

Nonaka, T., Watanabe, S.T., Iwatsubo, T., Hasegawa, M., 2010. Seeded aggregation and toxicity of -synuclein and tau: CELLULAR MODELS OF NEURODEGENERATIVE DISEASES. J. Biol. Chem. 285, 34885-34898. https://doi.org/10.1074/jbc. M110.148460.
Opattova, A., Filipcik, P., Cente, M., Novak, M., 2013. Intracellular degradation of misfolded tau protein induced by geldanamycin is associated with activation of proteasome. J. Alzheimer's Dis. 33, 339-348.

Partyka, A., Wasik, A., Jastrzębska-Więsek, M., Mierzejewski, P., Bieńkowski, P., Kołaczkowski, M., Wesołowska, A., 2016. ADN-1184, a monoaminergic ligand with 5-HT6/7 receptor antagonist action, exhibits activity in animal models of anxiety. Naunyn Schmiedebergs Arch. Pharmacol. 389, 593-602. https://doi.org/10.1007/ s00210-016-1229-3.

Perez, M., Lim, F. Arrasate, M. Avila, J., 2000. The FTDP-17-linked mutation R406W abolishes the interaction of phosphorylated tau with microtubules. J. Neurochem. 74, 2583-2589.

Poppek, D., Keck, S., Ermak, G., Jung, T., Stolzing, A., Ullrich, O., Davies, K.J.A., Grune, T., 2006. Phosphorylation inhibits turnover of the tau protein by the proteasome: influence of RCAN1 and oxidative stress. Biochem. J. 400, 511-520. https://doi.org/10.1042/BJ20060463.

Prut, L., Belzung, C., 2003. The open field as a paradigm to measure the effects of drugs on anxiety-like behaviors: a review. Eur. J. Pharmacol. Anim. Models Anxiety Disord. 463, 3-33. https://doi.org/10.1016/S0014-2999(03)01272-X.

Ren, Y., Sahara, N., 2013. Characteristics of Tau oligomers. Front. Neurol. 4 https://doi. org/10.3389/fneur.2013.00102.

Renner, U., Zeug, A., Woehler, A., Niebert, M., Dityatev, A., Dityatev, A.G., Gorinski, N., Guseva, D., Abdel-Galil, D., Frohlich, M., Doring, F., Wischmeyer, E., Richter, D.W., Neher, E., Ponimaskin, E.G., 2012. Heterodimerization of serotonin receptors 5HT1A and 5-HT7 differentially regulates receptor signalling and trafficking. J. Cell. Sci. 125, 2486-2499. https://doi.org/10.1242/jcs.101337.

Roberson, E.D., Scearce-Levie, K., Palop, J.J., Yan, F., Cheng, I.H., Wu, T., Gerstein, H., Yu, G.-Q., Mucke, L., 2007. Reducing endogenous tau ameliorates amyloid -induced deficits in an Alzheimer's disease mouse model. Science 316, 750-754. https://doi. org/10.1126/science.1141736.

Rodríguez, J.J., Noristani, H.N., Verkhratsky, A., 2012. The serotonergic system in ageing and Alzheimer's disease. Prog. Neurobiol. 99, 15-41. https://doi.org/ 10.1016/j.pneurobio.2012.06.010.

Romero, G., Pujol, M., Pauwels, P.J., 2006. Reanalysis of constitutively active rat and human 5-HT7(a) receptors in HEK-293F cells demonstrates lack of silent properties for reported neutral antagonists. Naunyn Schmiedebergs Arch. Pharmacol. 374, 31-39. https://doi.org/10.1007/s00210-006-0093-y.

Sahara, N., Tomiyama, T., Mori, H., 2000. Missense point mutations of tau to segregate with FTDP-17 exhibit site-specific effects on microtubule structure in COS cells: a novel action of R406W mutation. J. Neurosci. Res. 60, 380-387. https://doi.org/ 10.1002/(SICI)1097-4547(20000501)60:3<380::AID-JNR13>3.0.CO;2-5.

Sakaue, F., Saito, T., Sato, Y., Asada, A., Ishiguro, K., Hasegawa, M., Hisanaga, S.-i., 2005. Phosphorylation of FTDP-17 mutant tau by cyclin-dependent kinase 5 complexed with p35, p25, or p39. J. Biol. Chem. 280, 31522-31529. https://doi. org/10.1074/jbc.M504792200.

Sanders, D.W., Kaufman, S.K., DeVos, S.L., Sharma, A.M., Mirbaha, H., Li, A., Barker, S. J., Foley, A.C., Thorpe, J.R., Serpell, L.C., Miller, T.M., Grinberg, L.T., Seeley, W.W., Diamond, M.I., 2014. Distinct tau prion strains propagate in cells and mice and define different tauopathies. Neuron 82, 1271-1288. https://doi.org/10.1016/j neuron.2014.04.047.

Sarkisyan, G., Hedlund, P.B., 2009. The 5-HT7 receptor is involved in allocentric spatial memory information processing. Behav. Brain Res. 202, 26-31. https://doi.org/ 10.1016/j.bbr.2009.03.011.

Sayas, C.L., Avila, J., Wandosell, F., 2002. Glycogen synthase kinase-3 is activated in

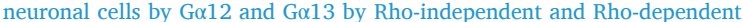
mechanisms. J. Neurosci. 22, 6863-6875.

Sheline, Y.I., West, T., Yarasheski, K., Swarm, R., Jasielec, M.S., Fisher, J.R., Ficker, W. D., Yan, P., Xiong, C., Frederiksen, C., Grzelak, M.V., Chott, R., Bateman, R.J., Morris, J.C., Mintun, M.A., Lee, J.-M., Cirrito, J.R., 2014. An antidepressant decreases CSF a $\beta$ production in healthy individuals and in transgenic AD mice. Sci. Transl. Med. 6, 236re4. https://doi.org/10.1126/scitranslmed.3008169.

Smit, M.J., Vischer, H.F., Bakker, R.A., Jongejan, A., Timmerman, H., Pardo, L., Leurs, R., 2007. Pharmacogenomic and structural analysis of constitutive $g$ protein-coupled receptor activity. Annu. Rev. Pharmacol. Toxicol. 47, 53-87. https://doi.org/ 10.1146/annurev.pharmtox.47.120505.105126.

Speranza, L., Chambery, A., Di Domenico, M., Crispino, M., Severino, V., Volpicelli, F., Leopoldo, M., Bellenchi, G.C., di Porzio, U., Perrone-Capano, C., 2013. The serotonin receptor 7 promotes neurite outgrowth via ERK and Cdk5 signaling pathways. Neuropharmacology 67, 155-167. https://doi.org/10.1016/j. neuropharm.2012.10.026.

Stamos, J.L., Chu, M.L.-H., Enos, M.D., Shah, N., Weis, W.I., 2014. Structural basis of GSK-3 inhibition by N-terminal phosphorylation and by the Wnt receptor LRP6. Elife 3, e01998.

Su, S.C., Tsai, L.-H., 2011. Cyclin-dependent kinases in brain development and disease. Annu. Rev. Cell Dev. Biol. 27, 465-491. https://doi.org/10.1146/annurev-cellbio092910-154023.

Tai, H.-C., Serrano-Pozo, A., Hashimoto, T., Frosch, M.P., Spires-Jones, T.L., Hyman, B. T., 2012. The synaptic accumulation of hyperphosphorylated Tau oligomers in Alzheimer disease is associated with dysfunction of the ubiquitin-proteasome system. Am. J. Pathol. 181, 1426-1435. https://doi.org/10.1016/j. ajpath.2012.06.033.

Takahashi, S., Saito, T., Hisanaga, S., Pant, H.C., Kulkarni, A.B., 2003. Tau Phosphorylation by cyclin-dependent Kinase 5/p39 during brain development reduces its affinity for microtubules. J. Biol. Chem. 278, 10506-10515. https://doi. org/10.1074/jbc.M211964200. 
Thathiah, A., De Strooper, B., 2011. The role of G protein-coupled receptors in the pathology of Alzheimer's disease. Nat. Rev. Neurosci. 12, 73-87. https://doi.org/ 10.1038/nrn2977.

Thijssen, E.H., La Joie, R., Wolf, A., Strom, A., Wang, P., Iaccarino, L., Bourakova, V., Cobigo, Y., Heuer, H., Spina, S., VandeVrede, L., Chai, X., Proctor, N.K., Airey, D.C. Shcherbinin, S., Duggan Evans, C., Sims, J.R., Zetterberg, H., Blennow, K., Karydas, A.M., Teunissen, C.E., Kramer, J.H., Grinberg, L.T., Seeley, W.W., Rosen, H., Boeve, B.F., Miller, B.L., Rabinovici, G.D., Dage, J.L., Rojas, J.C., Boxer, A L., 2020. Diagnostic value of plasma phosphorylated tau181 in Alzheimer's disease and frontotemporal lobar degeneration. Nat. Med. 26, 387-397. https://doi.org/ 10.1038/s41591-020-0762-2.

Upton, N., Chuang, T.T., Hunter, A.J., Virley, D.J., 2008. 5-HT6 receptor antagonists as novel cognitive enhancing agents for Alzheimer's disease. Neurotherapeutics 5 , 458-469. https://doi.org/10.1016/j.nurt.2008.05.008.

Wang, Y., Mandelkow, E., 2015. Tau in physiology and pathology. Nat. Rev. Neurosci. 17, 22-35. https://doi.org/10.1038/nrn.2015.1.

Wang, J.-Z., Xia, Y.-Y., Grundke-Iqbal, I., Iqbal, K., 2013. Abnormal hyperphosphorylation of Tau: sites, regulation, and molecular mechanism of neurofibrillary degeneration. J. Alzheimer's Dis. 33, S123-S139.
Westrich, L., Haddjeri, N., Dkhissi-Benyahya, O., Sánchez, C., 2015. Involvement of 5HT7 receptors in vortioxetine's modulation of circadian rhythms and episodic memory in rodents. Neuropharmacology 89, 382-390. https://doi.org/10.1016/j. neuropharm.2014.10.015.

Wirth, A., Holst, K., Ponimaskin, E., 2016. How serotonin receptors regulate morphogenic signalling in neurons. Prog. Neurobiol. 151, 35-56. https://doi.org/ 10.1016/j.pneurobio.2016.03.007.

Wlodarczyk, J., Woehler, A., Kobe, F., Ponimaskin, E., Zeug, A., Neher, E., 2008. Analysis of FRET signals in the presence of free donors and acceptors. Biophys. J. 94, 986-1000. https://doi.org/10.1529/biophysj.107.111773.

Zack, G.W., Rogers, W.E., Latt, S.A., 1977. Automatic measurement of sister chromatid exchange frequency. J. Histochem. Cytochem. Off. J. Histochem. Soc. 25, 741-753. https://doi.org/10.1177/25.7.70454.

Zweig, R.M., Ross, C.A., Hedreen, J.C., Steele, C., Cardillo, J.E., Whitehouse, P.J., Folstein, M.F., Price, D.L., 1988. The neuropathology of aminergic nuclei in Alzheimer's disease. Ann. Neurol. 24, 233-242. https://doi.org/10.1002/ ana.410240210. 